\title{
Marc Felfe*
}

\section{Schlüssel oder Peitsche? Schulgrammatik im Spagat School Grammar: A Balancing Act Between Helpful Tool and Punishment?}

https://doi.org/10.1515/zgl-2020-2005

\begin{abstract}
In this essay I understand school grammar as academic grammar for future teachers. It aims at linguistic awareness, not linguistic knowledge, which is an essential common ground with grammar lessons at school. It is about exciting insights into the structure of language.

In the first section, the discourse on school grammar is examined. I will put a focus on the cultivated negative image of school grammar in history and then contrast it with practical expectations of use. Thereafter the essential linguistic foundations are outlined, which have been neglected in school grammar for far too long, being afraid of linguistic theory: valency and constituency. Afterwards, the area of tension between first and second language in terms of school grammar will be explored. Finally, I sketch school grammar as a basis for error correction and evaluation.
\end{abstract}

$1 \quad$ Schulgrammatik zwischen Peitsche und Schlüssel?

2 Schulgrammatik zwischen Wissen, Anwendung und Diskurs

3 Schulgrammatik: eine Grammatik zwischen linguistischen Theorien?

3.1 Verbvalenz und Satzglieder

3.2 Wortgruppen und Attribute

4 Schulgrammatik zwischen Erst- und Zweitsprachperspektive

5 Schulgrammatik zwischen falsch und richtig?

6 Fazit

Literatur

\footnotetext{
*Kontakt: Dr. Marc Felfe: Humboldt-Universität zu Berlin, Sprach- und literaturwissenschaftliche Fakultät, Institut für deutsche Sprache und Linguistik, Unter den Linden 6, D-10099 Berlin, E-Mail: marc.felfe@german.hu-berlin.de
} 


\section{Schulgrammatik zwischen Peitsche und Schlüssel?}

In dem Tübinger Hausbuch ${ }^{1}$ aus dem 15. Jahrhundert nimmt die Grammatik nicht nur die Spitzenstellung unter den septem artes liberales ein. In ihrer rechten Hand hält sie zudem eine Peitsche. Die erste Assoziation zur Schulgrammatik ist der Rotstift. Nietzsche (2017: 34) verteidigt in einem 1872 gehaltenen Vortrag die lateinische und griechische Schulgrammatik im Kampf gegen „grammatische und orthographische Grillen und Unarten“ der Alltagssprache.

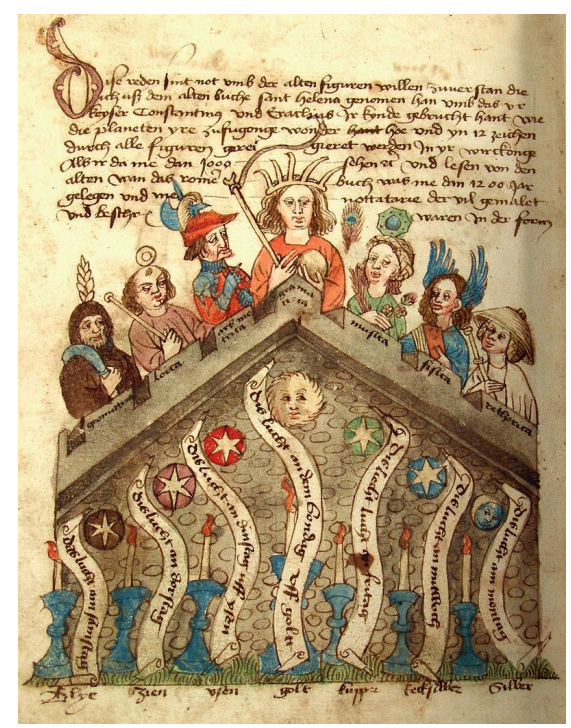

Abbildung 1: Tübinger Hausbuch. Von links nach rechts: Geometrie, Logik, Arithmetik, Grammatik (in der Mitte), Musik, Physik (anstatt der Astronomie), Rhetorik.

$\mathrm{Zu}$ jenem Bild passt auch die Allegorie der Grammatik in De nuptiis Philologiae et Mercurii (Die Hochzeit der Philologie mit Merkur) von Martianus Capella. Er stattet die Grammatik mit chirurgischem Besteck aus. Denn eine ihrer Aufgaben bestehe darin, den Kindern die grammatischen Fehler aus der Zunge zu schnei-

1 Tübinger Hausbuch. Handschrift. Universitätsbibliothek Tübingen, Md 2, fol. 320v. http://idb. ub.uni-tuebingen.de/diglit/Md2 
den und sie so von ihnen zu heilen. ${ }^{2}$ Bei einer bundesweiten Repräsentativerhebung ermitteln Gärtig et al. (2010: 212), dass die Befragten „an erster Stelle und mit großem Abstand" Schule und Lehrer in der Pflicht sehen, sich um die deutsche Sprache „zu kümmern“. Vor dem Hintergrund von Sprachwandel und -pflege meinten 78,4\% der Befragten, dass mehr für die deutsche Sprache getan werden“ müsse.

Im Tübinger Hausbuch trägt die Grammatik eine Krone und nimmt die Spitzenstellung unter den sieben freien Künsten ein. Die Grammatik strukturiert das Wissen und die Wissensbestände in Texten. Sprache ist die diferentia specifica des Menschen. Es geht um die Vernunftbegabung, Sprache als deren Ausdruck und Grammatik als das hinter ihr liegende System.

Die Enzyklopädie Margarita philosophica von Georg Reisch, im Jahr 1503 zum ersten Mal veröffentlicht, enthält ebenfalls den Kanon der sieben freien Künste. Die Grammatik wird aber ganz anders dargestellt, nämlich liebevoll einem Kind zugewandt. $^{3}$

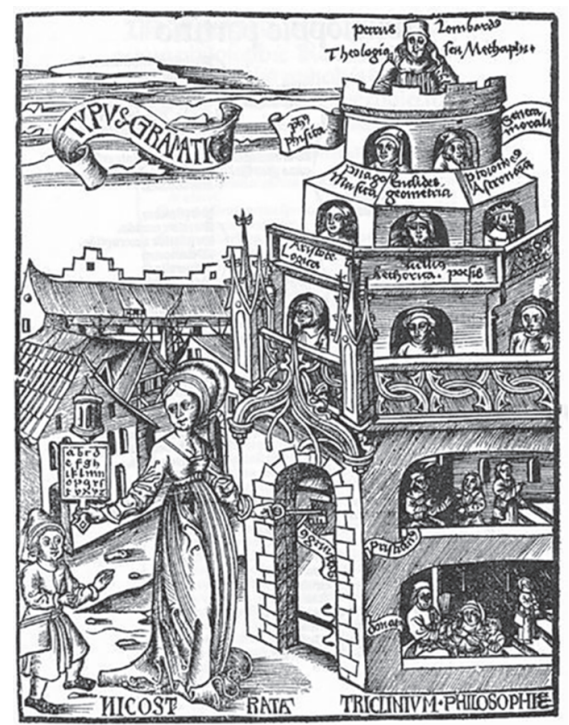

Abbildung 2: Typus Grammaticae aus der 4. Auflage der Margarita philosophica von Georg Reisch.

2 Der Text stammt aus dem 5.-6. Jhd. Übersetzt mit einer Einleitung, Inhaltsübersicht und Anmerkungen versehen von Hans Günter Zekl. Buch III: Vorstellung und Vortrag der Grammatik. Würzburg: Königshausen \& Neumann, 2005, S. 89-122.

3 Gregor Reisch. Margarita philosophica. 4. Auflage. Basel, 1517, S. VI: Typus grammaticae. Künstler unbekannt. https://upload.wikimedia.org/wikipedia/commons/7/78/Gregor_Reisch_-Margarita_philosophica_-_4th_ed._Basel_1517_-_p._VI_-_Typus_grammaticae_-_500ppi.jpg 
Auch hier lässt sich die Grammatik verschieden deuten. Entweder gibt sie mit der Tafel zur Alphabetisierung in ihrer rechten Hand einfach den lesenden Zugang zum Wissen der Zeit. Grammatik wird so auf die Funktion reduziert, in die Kultur der Schrift einzuführen - und damit gleichzeitig überfordert. Oder aber die Alphabetisierung ist nur eine Vorausetzung für jenen Zugang. Schließlich gibt sie im Sinne von Grammatik als Vernunft den Turm des Wissens frei, schließt ihn auf mit dem Schlüssel in ihrer linken. Die erste Station im Turm führt dann zu Donat, der Schulgrammatik. Und Donat droht wiederum mit Ruten.

Grammatik zwischen Peitsche und Schlüssel? Beide Bilder sind zu stark. Aber der Gegensatz, den jene Bilder vermitteln, lässt sich durchaus auf die Schulgrammatik übertragen. Allerdings nicht im Sinne eines Dilemmas wie z. B. Nilsson (2002), sondern im produktiven Bild eines zu meisternden Spagats. In diesem Sinne werde ich die Schulgrammatik in vier Abschnitten vor dem Hintergrund verschiedener Spannungsfelder darstellen.

In dem folgenden zweiten Abschnitt geht es um die Schulgrammatik nicht mit einer Peitsche, sondern unter der Peitsche eines lange vorgeprägten Negativdiskurses. Als eine seiner Quellen werden überzogene Nutzenerwartungen dargestellt, welche in Verbindung mit einem notorischen Diskurs über die Nutzlosigkeit des Grammatikunterrichts stehen.

Abgekoppelt von jenem Diskurs wird im dritten Abschnitt gezeigt, dass ein tatsächliches Problem des Grammatikunterrichts darin besteht, dass seine fachwissenschaftlichen Inhalte im Bereich der Satzanalyse nicht nur auf einem alten Stand, sondern ohne Fundament sind. Dies wird hauptsächlich auf Angst vor Theorie zurückgeführt. Anhand von zwei für die Syntax elementaren Strukturgrößen, der Verbvalenz und der Wortgruppe, wird eine dringend notwendige Erneuerung für einen Teil der Schulgrammatik skizziert. Einerseits geht es mir darum zu zeigen, wie wichtig profundes Wissen ist, um Sprachstrukturen zu verstehen und zu erklären (Schlüssel). Andererseits kann somit eine spannende linguistische Ausbildung von Lehrerinnen und Lehrern dringend nötige inhaltliche Veränderungen des Grammatikunterrichts unterstützen. Schulgrammatik wird hier primär als eine Grammatik für Lehrerinnen und Lehrer verstanden. Somit geht es nicht um sprachliches Können, sondern um metasprachliches Wissen. Im Vordergrund steht Sprache als linguistischer Gegenstand im Rahmen der akademischen Ausbildung.

Im vierten Abschnitt geht es um die Anforderungen an die Schulgrammatik vor dem Hintergrund von Deutsch als Erst- und Zweitsprache. Es wird gezeigt, dass dies aus fachwissenschaftlicher Sicht ein Mehr an grammatischem Wissen erfordert. In Bezug auf die Schul- und Bildungssprache wird zudem der Mythos des perfekten Muttersprachlers thematisiert.

Der letzte Abschnitt widmet sich der schulgrammatischen Bewertung sprachlicher Strukturen. Hier geht es um einen differenzierten Fehlerbegriff und ein Ver- 
ständnis für Variation. Denn diese sind die fachwissenschaftlichen Bedingungen für eine vernünftige Korrektur (Peitsche).

\section{Schulgrammatik zwischen Wissen, Anwendung und Diskurs}

In seinem Aufsatz Wieviel Grammatik braucht der Mensch? konstatiert Helbig, „dass die Grammatik zunehmend im Gerede ist“ (Helbig, 1992a: 150). Bei einem Blick in jenes ,Gerede‘ zeichnet sich ein recht düsteres Bild ab. So beschreibt Ulshöfer (1967: 108) die Schulgrammatik als eine leidige, langweilige und wirkungslose Angelegenheit für Schüler. ${ }^{4}$ Von ähnlichen Negativerfahrungen berichten Ivo und Neuland (1991: 437). Die Befragten würden sich nicht gerne an ihren Grammatikunterricht erinnern und wüssten, nach Selbsteinschätzung, nur wenig über die Grammatik ihrer Muttersprache. Bremerich-Vos (1999: 41) berichtet von Schülern, die das Gefühl hatten, dass ihre Lehrer mit Grammatik nicht viel anfangen konnten und diese lustlos unterrichtet oder ganz gemieden hätten. Deutschlehrer würden „mit zunehmendem Widerwillen“ die traditionelle Schulgrammatik unterrichten, so Steinig und Huneke (2015: 167). ${ }^{5}$ Vor jenem Hintergrund schreibt Köller (1997: 9): „Das Merkwürdige am Grammatikunterricht ist, daß es ihn immer noch gibt. Obwohl die Mehrzahl der Schüler und Lehrer ihn eher zu hassen als zu lieben scheint, hat ihn noch nicht der Auszehrungstod ereilt. “ Während Köller (1997) es noch vorsichtig (oder ironisch?) ausdrückt, behaupten Habermann et al. (2009: 143): „Für die meisten Schülerinnen und Schüler und auch die meisten Sprecherinnen und Sprecher ist die Grammatik ein Hassobjekt“. Nilsson (2002: 23) hinterfragt nicht den Diskurs über die Grammatik, sondern folgert aus ihm:

Grammatik ist ein Gebiet, das mit vielen Ängsten verbunden ist. Nicht nur die Schüler betrachten sie als Qual, manchmal sogar als disziplinarische Maßnahme, sondern auch die Lehrer sehen in ihr ein Schreckgespenst.

\footnotetext{
4 Aus Gründen einfacherer Lesbarkeit benutze ich in diesem Aufsatz das generische Maskulinum. Ich hoffe, dass nach dringend notwendigen Debatten und Praktiken, die Geschlechter und Identitäten explizit zu nennen, die Zeit für ein generisch diverses Verständnis der einen Form reif ist.

5 Steinig und Huneke (2015: 167) konkretisieren jedoch das Problem. Es geht um die ,alte Schulgrammatik“. Daher fordern Steinig und Huneke (2015: 177-183) u. a. die Einführung des topologischen Modells und der Verbvalenz in die Schulgrammatik.
} 
Stimmen wie Häcker (2009: 310), der bei einer Befragung von 219 Deutschlehrern ermittelt, dass $74 \%$ gerne Grammatik unterrichten würden, werden kaum wahrgenommen.

Ein kurzer Blick in den Diskurs über den Grammatikunterricht bringt vor allem eines zu Tage, nämlich die emotional aufgeladene Reproduktion eines Negativbildes. Andresen (1985: 129) zieht daraus den sonderbaren Schluss: „Die negative Besetzung des Sprachunterrichts dürfte damit zusammenhängen, daß es hier gerade nicht um einen Gegenstand geht, der den Lernenden weit entfernt und daher gleichgültig ist.“ Dies mutet wie eine Ehrenrettung von so viel Hass, Schreckgespenst, Langeweile und Widerwille an.

Boettcher (1994: 170) schreibt, dass seit Anfang der achtziger Jahre die Kämpfe um den Grammatikunterricht „Zitate wurden“ und sich nichts mehr bewegt habe. Was er nicht schreibt, ist, dass es sich um die Reproduktion von Negativurteilen handelt. Deren Vorlagen stammen spätestens aus der Aufklärung. So kritisiert Herder (1972: 49) im Journal meiner Reise im Jahr 1769 zuerst die grammatischphilosophische Abrichtung der Kinder anhand der lateinischen Schulgrammatik. Aus seinem Donat habe sich niemals Verstehen entwickelt. ${ }^{6}$ Herder (1972: 114115) wendet sich gegen die aus dem Lateinischen übernommene Schulgrammatik in der Muttersprache und schreibt: „Gehe also in eine Schule der Grammatiker hinein: eine Welt älternder Seelen, unter einem veralteten Lehrer“ und fordert „Weg also Grammatiken und Grammatiker“. Die Begründung ist einfach: „Der erste abstrakte unverstandene Begriff ist Gift“.

Es ist nachvollziehbar, dass eine vom Schriftlatein abgemeißelte Paradigmengrammatik in der Aufklärung abgelehnt wird, insbesondere dann, wenn sie auf lebendiges Deutsch gezwängt wird und diesem dabei z. B. einen Vokativ unterjubelt (o Herr). ${ }^{7}$ Man will nicht übernehmen, sondern schaffen, sich nicht an Fremdes halten, sondern Eigenes schöpfen (wie die Idee der natürlich aus inneren Begriffen geschaffenen Ursprache). So verwundert es nicht, dass Herder (1810: 15) in seiner 1780 gehaltenen Weimarer Schulrede anlässlich der Abschlussprüfung durchaus Grammatik fordert, Grammatik als metasprachliche Reflexion, Grammatik als „Leitseil im großen Labyrinth der Sprachen und Worte“. Es sei dahingestellt, ob „ein Mensch, der in seinem Leben keine Grammatik gelernt hat“, deshalb auch „nicht sicher sprechen und schreiben“ könne. Mit dem Fokus auf metasprachliche Reflexion geht es um die Nähe zwischen Kreation und Reproduktion im Sinne der Humboldt'schen energeia sowie später um ein unbe-

6 Grimm (1819: X) wird ähnlich fragen, was ein wahrer Dichter wohl ,aus Adelung“ gelernt habe bzw. ob er „ihn nachgeschlagen“ habe.

7 So z.B. in Roth, Georg M. (1799): Systematische deutsche Sprachlehre für Schulen. Giessen: Heyer, S. 110, § 99. 
wusstes Schaffen und Auflösen von Proportionsgleichungen bei Hermann Paul (1880).

Interessant ist, dass nicht nur die Kritik am bestehenden Grammatikunterricht, sondern auch die Forderung nach seiner Abschaffung bis in die jüngere Zeit wiederholt werden, wenn auch eher als Abkehr von formalen Sprachbetrachtungen, u. a. von Gaiser (1950), Weisgerber (1957), Ingendahl (1999). Wer nicht erwartet, dass jede sprachliche Form eine Funktion hat, die zudem ohne sie nicht vermittelbar wäre und wer Funktionen im Sprachbau und nicht in der Welt betrachtet, für den kann eine bei der Form ansetzende Sprachbetrachtung äußerst spannend sein.

Aus Grammatik ein Hassobjekt zu machen - und/oder daraus eine besondere Nähe zur Grammatik zu assoziieren, das alles hat mit Grammatik nichts zu tun und hilft in keiner Weise tatsächliche und kultivierte Probleme der Schulgrammatik zu lösen. Offensichtlich handelt es sich um ein Eintrittsbillet in den Diskurs über Schulgrammatik, und zwar, härter formuliert, in einen etablierten akademischen Diskurs, in dem es kaum um grammatische Inhalte geht.

Im nicht-akademischen Sprachgebrauch finden sich keine statistisch ernstzunehmenden Kookkurenzen zwischen Grammatik und Hass. Im Deutschen Referenzkorpus (DeReKo) ${ }^{8}$ finden sich gerade einmal 2 Belege, in denen Grammatik als Objekt des Hasses perspektiviert wird. ${ }^{9}$ Die häufigsten mit Grammatik vorkommenden Wörter sind nach Rang aufgeführt: Rechtschreibung (und Grammatik), (Grammatik) pauken, lernen, büffeln, (Grammatik und) Wortschatz sowie Wortbildung. Die Datenlage sieht auch im deutschen Teil des Web as Corpus (DeWaC) ${ }^{10}$ nicht anders aus. Obwohl dieses Korpus auch webbasierte Texte von privaten Homepages, von Blogs und Foren beinhaltet, lassen sich Hass und Grammatik im Sprachgebrauch nicht als miteinander assoziierte Begriffe nachweisen. Beide kommen ein einziges Mal im Sinne von Grammatik hassen vor (0.00 per million). ${ }^{11}$ Das ist ein schöner Befund, da er jeder emotionalen Aufladung widerspricht. Die negativ belegten Verben büffeln und pauken scheinen mir eher typisch für das unfreiwillige Lernen in der Schule im Allgemeinen als für das spezielle Lernen von Grammatik.

8 Über COSMAS II recherchier- und analysierbar. https://cosmas2.ids-mannheim.de/cosmas2web/faces/investigation/archive.xhtml (20.03.2018).

9 Das Lemma hassen kommt 67.916 mal vor und Grammatik 22.950 mal.

10 CQP-Interface der Humboldt-Universität zu Berlin. https://korpling.german.hu-berlin.de/ cqpwi (20.03.2018).

11 Das Lemma hassen kommt 25.226 Mal vor (15.50 per million) und das Lemma Grammatik 8.760 Mal (5.38 per million). 
Es geht hier nicht um Schönfärberei von tatsächlichen Problemen des Grammatikunterrichts. Diese werden im folgenden Abschnitt besprochen. Vielmehr geht es um die nüchterne Betrachtung eines Diskursproblems.

Wer Lehrer wird, muss Grammatik unterrichten und sollte bestmöglich darauf vorbereitet werden. Nach Eisenberg (2013: 8) geht es darum: Sprache zu können, zu reflektieren, Sprachwissen theoretisch zu fundieren sowie Sprachtheoretisches zu kennen und zu reflektieren. Lehrer müssen (meta)sprachliches Wissen vermitteln, entwickeln und beurteilen. In den Bildungsstandards im Fach Deutsch für den Primarbereich (2004), ${ }^{12}$ den grammatikintensivsten Bereich, werden u. a. die folgenden grammatischen Fertigkeiten gefordert: Wörter strukturieren und bilden, sammeln und ordnen, sprachliche Einheiten operational umstellen, ersetzen, weglassen, ergänzen, Deutsch als Erst- mit Deutsch als Zweitsprache sowie die Standardsprache mit Dialekten vergleichen.

Zwar ist auch Boettcher (1994: 170) in dem dargestellten Negativdiskurs verfangen und schreibt von einem „Teufelskreis“ zwischen ,grammatikgeschädigten Schüler[n]“, die Lehrer werden und ihre schlechten Erfahrungen bzw. nichts weitergeben. ${ }^{13}$ Dem düsteren Bild folgt aber ein produktiver Vorschlag, nämlich jenen Teufelskreis in einer soliden und anregenden fachlichen Ausbildung von Lehrern an der Universität zu durchbrechen.

Auch Eisenberg (2004: 4-5) bestimmt die Schulgrammatik in erster Linie als eine Grammatik für Lehrer. Es geht primär um ein grundlegendes Verständnis von Form-Funktionszusammenhängen, welches der Vermittlung dienen soll. Die zukünftigen Lehrer, so Eisenberg (2004: 19), sollen „in die Lage versetzt werden, ihr Wissen zu gebrauchen, ohne es unbedingt preiszugeben“. Zudem machen Steinig und Huneke (2015: 22) sowie Ossner (2015: 75-76) darauf aufmerksam, dass solides fachwisschenschaftliches Wissen Voraussetzung für fachdidaktisches Wissen ist. Zu Letzterem gehört die Unterscheidung zwischen explizitem kategorialen Grammatikwissen und grammatischem Können. Die akademische Ausbildung unterscheidet sich wesentlich vom grammatischen Lernen in der Schule. Denn dieses ist, wie Feilke und Tophinke (2016: 7) schreiben, „erwerbsorientiert, kommunikativ motiviert und zielt auf prozedurale Fähigkeiten. Damit sind die Ziele pragmatisch näherliegend als ein auf Systematizität und die kategoriale Struktur der Sprache hin angelegter Grammatikunterricht.“ (kursiv im Original).

12 Beschlüsse der Kultusministerkonferenz. Herausgegeben vom Ständigen Sekretariat der Kultusministerkonferenz. Beschluss vom 15.10.2004. https://www.kmk.org/themen/allgemeinbildende-schulen/unterrichtsfaecher/deutsch.html (20.04.2018).

13 Fast das gleiche Bild eines zu durchbrechenden Teufelskreises findet sich bei Braun (2013: 17). 
Die akademische Schulgrammatik muss natürlich an die in der Schule zu vermittelnde Grammatik anschlussfähig sein. Das beinhaltet vier wesentliche Punkte. Sie muss erstens Hintergrundwissen zu den Inhalten des Unterrichts sowie Kenntnisse über den Erwerb und Aufbau metasprachlicher Kompetenz vermitteln. Bei Letzterem geht es nach Bredel (2013: 126) um ein Zurücktreten der Sprecher von primärsprachlichem Handeln, um ihre Aufmerksamkeit auf sprachliche Strukturen zu richten. Zweitens muss sie dazu befähigen, die fachliche Seite von Schulbüchern, Arbeitsmaterialien und von traditionellen Kategorien der Schulgrammatik zu hinterfragen. Drittens sollte sie einen differenzierten Fehlerbegriff als eine Grundlage von Korrektur und Bewertung erlauben. Viertens sollte sie es künftigen Lehrern ermöglichen, sich im Diskurs über Schulgrammatik zu positionieren. Voraussetzung für diese vier Punkte ist, dass Schulgrammatik spannend und ernsthaft als akademisches Fach gelehrt wird.

Im Folgenden werden die einzelnen Punkte kurz anhand von Beispielen dargestellt. Ausgenommen ist der dritte Punkt, die Fehlergrammatik, um die es im vierten Abschnitt gehen wird.

Deklarativ-analytisches Wissen wird über implizites Prozesswissen aufgebaut. Dies gilt als Methodik für die akademische Ausbildung und wird auch mehr und mehr für die Schule gefordert. ${ }^{14}$ Als klassischer Test zur Bestimmung von Satzgliedern gilt die Umstellprobe. Schulische Anwendung findet sich bei Menzel (1999: 15), wo die Umstellungsprobe direkt zu Satzgliedern führen soll. Erst einmal unabhängig von ihrer Anwendung in der Schule sollten zukünftige Lehrer operationale Verfahren als wertvolle Indizen zur Klassifizierung sprachlicher Einheiten kennen und anwenden lernen. Um Beweise allerdings handelt es sich nicht. So sind z. B. Satzglieder zu bedenken, die sich nicht voranstellen lassen (Ich habe es gesehen im Gegensatz zu ${ }^{\star}$ Es habe ich gesehen), Konstituenten, die kleiner als klassische Satzglieder sind (Gesehen habe ich es gestern) und solche, die größer sind (Gestern gesehen habe ich es).

Außerdem werden in Schulbüchern teils die Kasus, teils die Satzgliedfunktionen, meist beides als Mischkonzept erfragt. Wer oder was erfragt somit eine Substantivgruppe im Nominativ/Subjekt, wen oder was eine im Akkusativ/ Akkusativobjekt, wem eine im Dativ/Dativobjekt und wessen eine im Genitiv/ Genitivobjekt. Dies wird teilweise von Seiten der Didaktik und vollkommen von der Fachwissenschaft kritisiert. Viel zu lange war es so in den grundlegenden

14 Cf. Granzow-Emden (2014: 15) und speziell in Bezug auf L2-Lerner Housen et al. (2005: 238). Funke (2005: 232) zeigt anhand von Experimenten, dass die Arbeit mit Mustern über Analogieketten der Analyse ihrer Merkmale vorausgeht. Bredel (2013: 118) schreibt von extensionalen im Gegensatz zu intensionalen Begriffsdefinitionen. Praktisch wird so der Stoff in den meisten älteren und neuen (didaktischen) Grammatiken des Deutschen dargestellt. 
grammatischen Fachausdrücken der Kultusministerkonferenz (1982) aufgelistet und findet sich in allen mir bekannten Schulbüchern. Ein einprägsames Beispiel für das Scheitern jener Erfrage-Operation gibt Boettcher (1994: 173-174) in Form eines transkribierten Dialogs zwischen einer Lehrerin und ihren Schülern. Erst in dem seit 2019 gültigen Verzeichnis grundlegender grammatischer Fachausdrücke der Kultusministerkonferenz wird die Erfragung von Satzgliedern nicht mehr als Erklärung oder anstelle einer Erklärung genutzt.

Zur Verortung im Diskurs über die Schulgrammatik muss eine weitere Quelle des Negativbildes aufgezeigt werden. Ich nenne sie die Nutzenfalle. Einerseits geht es um die ebenfalls zum guten Ton gewordene Klage über das schlechte grammatische Wissen von Schulabgängern und Studienanfängern. Andererseits handelt es sich um überspannte praktische Erwartungen an den Grammatikunterricht. Auch jene Erwartungen sind wissenschaftsfern. Die Vorstellung, dass aus explizitem grammatischen Wissen ein grammatisches Können im Sprachgebrauch folge, bezeichnet Bredel (2013: 98) als einen „der vielleicht schwerwiegendsten Irrtümer der Sprachdidaktik“. Erkenntnistheoretisch hat Ryle (2009: 19) jenen Irrglauben in seinem 1949 zuerst veröffentlichten Werk The Concept of Mind als „intellectualist legend“ bezeichnet. Dieser zufolge setzen überlegte Handlungen entsprechendes explizites Regelwissen voraus. Aber schon das Abwägen von explizitem Regelwissen (knowing that) ist eine Handlung, die entsprechendes Handlungswissen (knowing how) erfordere. Wenn dieser, der intellektualistischen Legende zufolge, immer ein explizites Regelwissen vorausgehen müsse, käme es zu keiner überlegten Handlung. So schreibt Ryle (2009: 19): „Efficient practice precedes the theory of it“.

Karmiloff-Smith (1992: 20) hat ein Reanalysemodell entwickelt, in dem zwischen impliziten Wissensformen und verschiedenen Stufen von explizitem Wissen unterschieden wird. Dessen höchste Stufe, so Karmiloff-Smith (1992: 61), sei durch verbalisierte Sprachreflexionen empirisch gut beobachtbar. Aber explizite Grammatikkenntnisse seien nicht nur an entsprechende Terminologie und Regelformulierungen gebunden, sondern entwickelten sich bereits frühzeitig durch den Gebrauch sprachlicher Strukturen. Als Indikator hierfür wertet Karmiloff-Smith (1992: 48) Selbstkorrekturen. Ebenso zeigt Karmiloff-Smith (1992: 19-20, 31, 39), dass ein Anstieg metasprachlichen Wissens zwischenzeitlich zur Abnahme sprachlichen Könnens führt. Sie schreibt daher von $u$-förmigen Entwicklungskurven. Die wachsende Sprachbewusstheit verunsichere die automatisierte Reproduktion sprachlicher Formen und führe durch Neuordnungen der Wissensbestände $z u$ regelgeleiteten Übergeneralisierungen, die erst später wieder korrigiert werden. Dies bestätigen auch Untersuchungen von Kany und Schöler (2007: 60) zum Erwerb der Pluralformen im Deutschen. So werden bereits korrekt reproduzierte Pluralformen wie Bücher durch schrittweise erworbene 
Regeln der Pluralbildung zu Buchs. Die Autoren bezeichnen jenen Prozess als ein ,Entlarven' der früheren Form Bücher als rein auswendig gelernt. Erst mit einsetzender Regeldifferenzierung werde zu einem dritten Erwerbszeitpunkt wieder die korrekte Pluralform Bücher produziert. Bredel (2005: 86-87) beschreibt analog die Erwerbsschritte der starken Verbflexion von schläft oder kam über schlaft und kommte zu schläft und kam.

Dauerhaft beklagt wird die scheinbare Wirkungslosigkeit des Grammatikunterrichts. So ermittelt Risel (1999: 57) bei einer Befragung von 105 Personen, dass $90 \%$ von ihnen einige, viele oder gravierende Lücken in ihrem Grammatikwissen sehen. Wie soll eine solche Aussage sinnvoll interpretiert werden? Schmitz (2003: 457) beklagt nach der Auswertung eines Grammatiktests mit ca. 200 Essener Studierenden die „erbärmlichen Trümmer grammatischen Grundwissens“ und bangt im Titel seines Aufsatzes um den Untergang des „grammatischen Abendlandes“. Trotz großzügiger Korrektur hätten, so Schmitz (2003: 452-453), 80\% der Befragten nur zwischen 8 und 12 von 30 Fragen richtig beantwortet. Lediglich 5 Personen hätten mehr als die Hälfte der Fragen richtig beantwortet. Die Aufgabenart, nämlich 30 grammatische Termini wie finites Verb, Genitiv, Prädikat zu definieren und je ein Beispiel anzugeben, hinterfragt Funke (2005: 99) zurecht und hält es für sinnvoller, Grammatikwissen an gegebenen sprachlichen Strukturen zu messen. Dürscheid (2007: 47) führt einen ähnlichen Test mit 73 Studierenden in Zürich durch, bei dem jedoch 71,3\% mehr als die Hälfte richtig beantworten. Schäfer und Sayatz (2017: 231-232) lassen 220 Studierende der Berliner Freien Universität grammatische Aufgaben aus Lehrbüchern der Klassenstufen 6-10 bearbeiten. Ein Viertel der Studierenden liegt, in universitären Noten ausgedrückt, bei 2,3 oder besser. Ein weiteres Viertel hat eine 3,7 oder schlechter. Zwar liegt der höchste Einzelwert unter den zehn Noten mit 15\% bei der Note 5. Der Median hingegen liegt bei 3,0. So schreiben Schäfer und Sayatz (2017: 232) dann auch: „es kann überhaupt nicht davon gesprochen werden, dass die schulische Ausbildung ohne Ergebnis geblieben wäre“. Auf den Inhalt der Tests und einzelne Ergebnisse komme ich im dritten Absatz zurück.

Die Untersuchungen von Dürscheid (2007) und Schäfer und Sayatz (2017) zeigen nüchtern und fernab vom bildungsbürgerlichen Verfallsdiskurs, dass pauschal nicht die Rede sein kann von „Trümmern“ und „Untergang“. Sie zeigen aber auch, dass Handlungsbedarf besteht. Denn zufriedenstellend sind die Ergebnisse nicht.

Der eingangs erwähnte Artikel von Helbig (1992b) Wieviel Grammatik braucht der Mensch? bezieht sich direkt auf den gleichnamigen Artikel von Gaiser (1950: 1), der explizite Grammatikkenntnisse mit der Harmonienlehre vergleicht. Sie seien für Liebhaber von Interesse, jedoch ohne praktischen Nutzen. Diese Aussage 
scheint genauso überspitzt wie die Annahme, dass Grammatik das analytische Denken fördere. ${ }^{15}$

Für Braun (2013: 25) verläuft die Nutzendiskussion in einer Wettbewerbssituation mit anderen Fächern zweigleisig. Einerseits gehe es um einen Primärnutzen. Hierunter wird das fachwissenschaftliche Wissen selbst verstanden. Dessen Anwendung beispielsweise für die Orthographie, in Bezug auf die Terminologie beim Fremdsprachenunterricht oder bei der Reflexion von Normen und Sprachgebrauch gelte als Sekundärnutzen. ${ }^{16}$ Ossner (1993: 323) schreibt, dass jene Nutzendiskussion nur in Bezug auf den Grammatikunterricht gestellt werde. Im Vergleich mit anderen Fächern wie Mathematik oder Biologie sei das einzigartig. Eine Erklärung hierfür vermutet Ossner (1993: 323) in der Tatsache, dass die Schüler bereits über implizites grammatisches Wissen verfügen, was in der Mathematik oder Biologie nicht der Fall sei. Hierauf werde ich im vierten Abschnitt noch einmal zurückkommen. Eine strikte Trennung in Primär- und Sekundärnutzen ist sicher nicht sinnvoll, da sie unweigerlich in die Nutzenfalle führt.

An dieser Stelle wird jener Nutzen-Druck erst einmal vor dem Hintergrund des Negativdiskurses verständlich. Wenn etwas Qual ist und Hass erzeugt, so muss es wenigstens durch entsprechenden Nutzen gerechtfertigt werden. Und je höher der Druck, umso verwertbarer muss der Nutzen (gute Noten beim Aufsatz?/ ein fehlerfreies Bewerbungsschreiben?/Interesse an Sprache?) sein. Somit nährt sich die Nutzenfalle indirekt auch wieder vom akademischen Negativdiskurs, der um sich selbst kreist. Zentral ist die Prüfung des möglichen Sekundärnutzens, bevor er postuliert wird. Köller (1997: 9) schreibt vom „Hass“ auf die Grammatik „als eine Art enttäuschter Erwartung“. Hier kommen wichtige, aber ganz und gar ungrammatische Fragen ins Spiel. Granzow-Emden (2014: 17) bemerkt nüchtern: „Grammatikunterricht zielt nicht unmittelbar auf den Sprachgebrauch. Zu einem angemessenen Sprachgebrauch kann nur der jahrelange Umgang mit Sprache führen - Zuhören, Sprechen, das Vorgelesen-Bekommen und Lesen [...]“. In Zeiten überhitzter Diskussionen um die Rechtschreibfähigkeiten ${ }^{17}$ muss vor einer zweiten Nutzenfalle gewarnt werden. Phonetische, phonologische, morphologische und syntaktische Kenntnisse sind unerlässlich, um grundlegende Prinzipien der Graphematik zu verstehen, auf welchen (größtenteils) die Ortho-

15 Köller (1997: 23) schreibt, dass Sprache als historisch gewachsenes System nicht logisch-analytisches Denken fördern könne. Dies erinnert an den späten Wittgenstein (1990: 159, § 108), der vom „Vorurteil der Kristallreinheit“ natürlicher Sprachen schreibt.

16 Für eine Übersicht über die traditionellen Begründungen des Gramamtikunterrichts verweise ich auf Dürscheid (2007: 57-58).

17 So titelt DER TAGESSPIEGEL vom 13.02.18 „Berlins Drittklässler können nicht schreiben“ und in der FAZ vom 26.01.18 steht in Bezug auf die Rechtschreibung „Wie sollen Lehrkräfte vermitteln, was sie selbst nicht können?“ 
graphie beruht. Jedoch darf der Wert des Grammatikunterrichts nicht mit den Ergebnissen von Rechtschreibtests gleichgesetzt werden. ${ }^{18}$ Die Nutzenfrage ist wichtig. Eine auf unmittelbare Messbarkeit reduzierte Antwort ist m. E. falsch.

Das wesentliche Ziel der Schulgrammatik besteht darin, metasprachliche Kompetenz aufzubauen. Dabei geht es um operatives Wissen und darauf aufzubauendes kategoriales Wissen. Es geht um ein Nachdenken über sprachliche Strukturen und das Verständnis sprachlicher Kreativität. Grammatik im Sinne des Sprachspiels von Wittgenstein (1990: 101, § 7; 138, § 66): Funktionalität und Prototypik anstelle logischer Regeln. Einige Grundlagen hierfür werden in den folgenden Abschnitten besprochen.

\section{Schulgrammatik: eine Grammatik zwischen linguistischen Theorien?}

Für die geforderte Anschlussfähigkeit der Schulgrammatik an den Grammatikunterricht bot lange das von Kultusministerkonferenz (1982) veröffentlichte Verzeichnis der grammatischen Fachtermini eine erste Orientierung. Das Verzeichnis war eine wesentliche Grundlage für den Grammatikunterricht und für die Zulassung von Lehrbüchern, weshalb es trotz der grundlegenden Neufassung durch die Kultusministerkonferenz (2019) nachwirkt. Hierin liegt bzw. lag ein echtes Problem der Schulgrammatik. Die aufgelisteten Fachausdrücke wurden nicht definiert und entzogen sich somit dem Verständnis. ${ }^{19}$ Dieses Verzeichnis entbehrte wesentlicher fachwissenschaftlicher Erkentnisse. So fand beispielsweise die Feldgliederung des Satzes gar keine Erwähnung. Syntaktische Relationen wie Dependenz und Konstituenz tauchten nicht auf. Granzow-Emden (2014: 10) schreibt: „Eine solche Wissenschaftsferne gibt es sonst in keinem Schulfach man stelle sich einen entsprechenden Chemie-, Physik- oder Biologieunterricht vor, der 150 Jahre Wissenschaft einfach ignoriert.“ Diese Kritik ist jedoch nicht neu. Einhundertvierzig Jahre zuvor schreibt Jolly (1874: 1):

Wenn [...] im Bereich der Naturwissenschaften eine Entdeckung gemacht wird, so pflegt nicht nur der Fabrikant [...] den Betrieb seiner Fabrik schleunig und geräuschlos umzugestalten, rasch tritt auch in der Schulliteratur ein Autor hervor, der den Fund des Gelehrten für die Zwecke des Unterrichts nutzbar macht. Die lebhafte Opposition, der zähe Widerstand macht sich dagegen geltend, jedesmal wenn Jemand versucht die Methode des sprachlichen Elementarunterrichts mit den Ergebnissen der Wissenschaft in Einklang zu bringen. (Jolly, 1874: 1)

18 Cf. Steinig und Huneke (2015: 18-19).

19 Cf. Topalovic und Dünschede (2014: 78), Granzow-Emden (2014: 9-10). 
Ganz deutlich wurde jene Wissenschaftsferne am Beispiel der Wortgruppe. In seinem für die moderne Syntax wichtigen Buch Was ist Syntax? Ein kritischer Versuch betont Ries (1894: 10, 56-60) die Notwendigkeit, Wortgruppen unterhalb der Satzgliedebene $\mathrm{zu}$ analysieren und damit die (logische) Satzzentriertheit der klassischen lateinischen Grammatik zu sprengen. Er fordert eine Syntax auf der Grundlage des Wortgefüges. Angeregt von jener Kritik überarbeitet Sütterlin (1907: V) seine erstmals 1897 erschienene Grammatik für Lehrer und Studierende, indem er syntaktische Gruppen unterhalb der Satzglieder systematisiert. Dennoch ist die Wortgruppe erst mehr als hundert Jahre nach Ries (1894) in der Schulgrammatik angekommen. Granzow-Emden (2014: 10, 14) fordert sie als „Tor zur Schulgrammatik“. Ihr bisheriges Fehlen korreliert mit einigen Ergebnissen der bereits angesprochenen Untersuchung von Schäfer und Sayatz (2017) zu den Grammatikkenntnissen von Studienanfängern. Schäfer und Sayatz (2017: 233237) zeigen, dass akute Probleme bei der Analyse von Substantivgruppen und der Bestimmung von Attributen bestehen. Für beide Einheiten sind Strukturbegriffe unabhängig und unterhalb von der Satzgliedebene nötig.

Jene Trennung zwischen Wissenschaft und Schulgrammatik macht Jolly (1874: 2) dafür verantwortlich, dass der elementare Grammatikunterricht ein „Jugendlustverderber“ sei. Im Desinteresse der Historisch-vergleichenden Sprachwissenschaft an Fragen der Schulgrammatik sieht Jolly (1874: 5) den wesentlichen Grund für die Kluft zwischen beiden. Endgültig sei die Trennung durch Grimms ,geharnischte Kriegserklärung gegen den Schulunterricht in deutscher Grammatik“ geworden, so Jolly (1874: 7). Es geht um die Vorrede zur 1. Auflage der Deutschen Grammatik. Darin hält Grimm (1819: IX-X) die deutschen Sprachlehren „für verwerflich, ja für thöricht“. Offensichtlich ist es nicht nur die einflussreiche Schulgrammatik von Becker (1845), die Grimm verwirft. Er hält in der Tradition aufklärerischer Diskurse muttersprachlichen Grammatikunterricht für überflüssig und damit für schädlich. Denn er hemme die von Natur aus angelegte freie Entfaltung des Sprachvermögens. Folglich könne es, so Grimm (1819: XI), außer der Wissenschaft auch keine „Grammatik der einheimischen Sprache für Schulen und Hausgebrauch [geben].“ Wie angekündigt, komme ich im vierten Abschnitt auf die Annahme des perfekten Muttersprachlers zurück. Für Grimm (1819: XIII) ist die Normativität der Schulgrammatik wissenschaftsfeindlich und sprachfern. Beziehungen zwischen Deskription und Präskription sieht er nicht. Er lehnt die zahlreichen Grammatiken ab, welche die deutsche Sprache „grammatisch behandeln“. Für Ivo (2011: 17) beginnt mit Grimm die Zeit, in der von deutscher Schulgrammatik „,nur noch verschämt die Rede“ ist.

Die Abgrenzung ist nachvollziehbar. Die sich etablierende neue Wissenschaft trennt sich von der Tradition. Ihr Ziel ist es nicht, wie bei dem als Schottelius bekannten Schottel (1663: 1) in der ersten Lobrede steht, die deutsche Sprache ,in 
richtige formam artis" $z$ u bringen, damit sie dem Lateinischen und Griechischen gleichwertig, ja überlegen werde. Die Grimm'sche Organismusidee von Sprache steht einer normierenden Grammatik diametral gegenüber. Die vergleichenden Sprachwissenschaftler interessieren sich nicht für die hochdeutsche Schriftsprache. Diese steht aber im Zentrum der Schulgrammatik. Adelung (1782) macht sie in der Vorrede seiner Schulgrammatik für die „frühe Bildung des Geschmacks“ verantwortlich. Grimm sieht keinen Sekundärnutzen von Grammatik. Um diesen geht es Becker (1845: XI), der den grammatischen Unterricht als „die eigentliche Turnschule des Geistes [...], in welcher sich vorzüglich die intellektuellen Kräfte entwickeln und üben“ beschreibt.

Allerdings erklärt dieser historische Bruch nicht die bis heute andauernde Wissenschaftsferne und ,Verschulung' der Schulgrammatik als Teil der Schulsprache und damit verbundener Rituale. ${ }^{20}$ Um diese zu verstehen, muss auf die 1970er Jahre verwiesen werden. In der Krise der Literaturwissenschaft und im Schwunge der 1968er Jahre wurde versucht, die überalterte Schulgrammatik durch die Generative Grammatik zu ersetzen und als wissenschaftliches (Erkenntnis-)Modell in die Schule zu bringen. Das vorhersehbare Scheitern wurde vielfach beklagt. ${ }^{21}$ Eisenberg (1976: 10-11) schreibt, dass von der erklärungsstarken generativen Theorie erwartet wurde, dass sie sich auch ganz selbstverständlich von allein erkläre. Letztlich sei die Generative Grammatik aber weder wirklich didaktisiert worden, noch tatsächlich in der Schule vermittelt. Die vorgenommenen Vereinfachungen (z.B. Verzicht auf Tiefenstrukturen, syntaktische Transformationen) hatten mit der Wissenschaft nicht mehr viel zu tun und führten zu „Mischgrammatiken“, so Eisenberg (1976: 13). Zudem wurde das Konzept der Kompetenz fälschlicherweise auf sprachpraktische Fertigkeiten bezogen, wie Schlipphack (2012: 79) schreibt. Das Ergebnis ist klar. Das Versagen der Generativen Grammatik in der Schule wurde, wie Eisenberg (1976: 9) bemerkt, mit der Nutzlosigkeit grammatischen Wissens gleichgesetzt. Im Zuge der kommunikativen Wende führt das Modell des situativen Grammatikunterrichts ${ }^{22}$ eher zu einer Reduktion (statt, wo möglich, zu situativer und funktionaler Einbindung) von Grammatik.

Auch vor diesem Hintergrund werden die angesprochenen Lücken und Unschärfen des lange Zeit gültigen Verzeichnisses grundlegender grammatischer

20 Hier muss zwischen Schulgrammatik und didaktischen Grammatiken wie z.B. Heringer (2014) unterschieden werden. Denn Letztere reflektieren den Forschungsstand. Heringer (2014) tut dies übrigens im Format des bereits angesprochenen Donats aus Frage und Antwort.

21 Was kaum bekannt sein dürfte, ist, dass bereits Jolly (1874: 17), der ja, wie dargestellt, eine inhaltliche Reform der Schulgrammatik forderte, vor „Grimmnachbetern“ warnte. Hierunter verstand er diejenigen, welche übereilt die damals junge Wissenschaft in die Schule bringen wollten, allerdings in einer Vulgarisierung“, der Grimm wohl nicht zugestimmt hätte.

22 Cf. Boettcher und Sitta (1978). 
Fachausdrücke der Kultusministerkonferenz (1982) verständlicher. Sie rührten aus Angst vor Theorie. So hieß es auf Seite drei, dass es sich um einen „Kompromiss unterschiedlicher sprachwissenschaftlicher Standpunkte“ handele. Die Fachausdrücke seien „keine Festlegung auf ein bestimmtes Grammatikmodell“. Wie somit die geforderte Offenheit gegenüber „dem Unterricht förderlichen Erkenntnissen aus der Wissenschaft“ garantiert werden sollte, ist unklar. Letztlich handelte es sich nicht um einen Kompromiss, sondern das Ausblenden von Theorie. Eine Folge war, dass viele Termini inhaltsleer blieben.

So wurde im Verzeichnis der Begriff Subjekt kommentarlos aufgeführt. Je nach Betrachtung müssen jedoch mindestens zwei Subjektbegriffe differenziert werden. Aus valenzgrammatischer Perspektive handelt es sich im Normalfall um die erste Ergänzung des Verbs. Unter satzsemantischer Perspektive steht das (idealerweise, aber keineswegs immer) referierende Subjekt dem darüber prädizierenden Prädikat (als Verbindung des verbalen Prädikators mit seinen weiteren Ergänzungen und Angaben) gegenüber. ${ }^{23}$ Erst die Begriffsbestimmung erlaubt Verständnis und kann Interesse wecken. Eine gute Schulgrammatik, welche in erster Linie dem Verständnis wesentlicher Form-Funktionszusammenhänge dienen muss, kann nicht untheoretisch sein. ${ }^{24}$

Wie könnten nun Lösungen aussehen? Vom Gießener Kreis, einer heute am Institut für deutsche Sprache in Mannheim angesiedelten Gruppe von Sprachwissenschaftlern und Sprachdidaktikern, liegt ein überarbeitetes Verzeichnis Schulgrammatischer Terminologie vor. ${ }^{25}$ In diesem sind nicht nur viele Lücken geschlossen, sondern die Begriffe werden erklärt und sind mit Beispielen versehen. Der Vorschlag des Gießener Kreises ging maßgeblich in das neue Verzeichnis grundlegender grammatischer Fachausdrücke von der Kultusministerkonferenz (2019) ein. Ohne hier auf das Verzeichnis im Einzelnen einzugehen, ist ganz wesentlich, dass sich dieses zwar ebenfalls durch „Offenheit gegenüber verschiedenen grammatischen Theorien“ auszeichnet. Hier aber werden „Bausteine aus verschiedenen Grammatiken integriert“26 - statt sie auszulas-

23 Matthews (1981: 104-106) stellt den valenziellen Subjektbegriff dem Objekt gegenüber, den satzsemantischen der gesamten Verbalphrase als Prädikat. Hierauf beruht der Schulbegriff vom Satzgegenstand, über den das Prädikat eine Aussage macht.

24 Das gilt letztlich genauso für die Kategorisierung und Korrektur von Fehlern. Cf. Lüdeling (2008: 131).

25 http://www.grammatischeterminologie.de/dateien/Vergleich_Grammatische_Terminologie_1982-2014.pdf Der Gießener Kreis hat sich 2009 konstituiert. Das revidierte Verzeichnis richtet sich vor allem an Lehrer und Studenten. Der Kreis wird unterstützt durch die Deutsche Gesellschaft für Sprachwissenschaft, den Deutschen Germanistenverband und das Symposion Deutschdidaktik.

26 http://www.grammatischeterminologie.de/konzeption.htm (20.03.2018). 
sen. ${ }^{27}$ Für sich genommen sollten jene Perspektiven wissenschaftlich gesichert sein, ohne jedoch ein theoretisches Modell zu bilden. Gleiches gilt für einzelne Termini. So argumentiert Reis (1982: 194) beispielsweise dafür, dass die relationale Beschreibungsgröße Subjekt im Deutschen nicht notwendig sei. Entsprechende Eigenschaften (Verbalkongruenz, Auslassung beim Imperativ, Koreferenz mit dem Reflexivum, Auslassung bei Infinitivkonstruktionen, Stellungsmöglichkeiten) lassen sich unter dem Begriff nominativische Nominalphrase in nicht-kopulativen Sätzen beschreiben. Da die Schulgrammatik aber kein geschlossenes wissenschaftliches Modell ist, muss sie nicht nach unbedingter Notwendigkeit, sondern Einsicht, Verständnis und Anschlussfähigkeit trachten. Daher schreibt der Gießener Kreis nicht von einer neuen, sondern von einer ,revidierten Terminologieliste“, da die hinter der traditionellen Terminologie stehende fachübergreifend bedeutsame Standardisierung nicht aufgegeben werden dürfe. ${ }^{28}$ Außerdem ist zu bedenken, dass der groß angelegte Versuch von Glinz (1952), eine neue grammatische Terminologie (für die Schulgrammatik) einzuführen, gescheitert ist. Dies liegt m. E. nicht an der Macht der Tradition, sondern daran, dass Glinz (1952) zwar erfolgreich die empirische Ermittlung der Satzglieder (anstelle der Becker'schen Metaphysik) einführt, dass aber die so ermittelten Kategorien bereits recht gut mit der traditionellen Terminologie erfasst werden können. ${ }^{29}$

Die wesentliche Herausforderung ist es nun, verschiedene Perspektiven einzunehmen und aufeinander zu beziehen. Daher wird im Folgenden die Bedeutung der Verbvalenz für ein Verständnis der Satzglieder und im Anschluss, darauf aufbauend, das Prinzip der Konstituenz für das Verständnis der Wortgruppe skizziert.

\subsection{Verbvalenz und Satzglieder}

Zum Verständnis der Begriffe Subjekt, Objekt, Adverbial muss der Blick vom prädikatsbildenden Verb(komplex) ausgehen, welches selbst nicht als Satzglied bestimmt wird. Als Prädikat bildet es das Zentrum des Satzes. Dessen Glieder hängen direkt vom Prädikat ab, stehen aber in unterschiedlichen Beziehungen

27 Ebenso Eisenberg (2004: 11), Housen et al. (2005: 238), Dürscheid (2010: 62-63), GranzowEmden (2014: 15) sowie Schäfer und Sayatz (2017: 243-244) im Gegensatz zu Schlipphack (2012), die die Generative Grammatik (Rektions- und Bindungstheorie) neben der traditionellen Schulgrammatik in der gymnasialen Oberstufe einführen will.

28 http://www.grammatischeterminologie.de/

29 Daher schreibt Erben (1955: 150) von einer „Überprüfung, Neudeutung und gegebenenfalls Neubezeichnung schon bekannter Einheiten und Kategorien“. 
zum ihm. Es geht um Valenz und Dependenz. Auch das neue Verzeichnis der Kultusministerkonferenz (2019: 40) enthält den Valenzbegriff.

Der Begründer der modernen Valenztheorie, Lucien Tesnière (1959: 102, § 1) beschreibt die Satzgrundlage mit der einprägsamen Metapher vom Verb bzw. dem Verbalkomplex als „petit drame“. Denn es beinhalte, eben wie ein Drama, ein Geschehen und in aller Regel Akteure (Ergänzungen) auf der einen Seite und Umstände (Angaben) auf der anderen Seite. Den Ergänzungen entsprechen im Satz primär das Subjekt und die Objekte, den Angaben (bei Ausschluss der Direktiva) die Adverbiale. Nur die Ergänzungen sind in der Verbvalenz als eine Art Stellenplan enthalten. Hierzu muss in die Schulgrammatik das aus den 1970er Jahren stammende Konzept der Grundvalenzen (vgl. Welke (1988: 63)) aufgenommen werden. Es handelt es sich um übliche Argumentpotentiale der finiten aktivischen Form (vgl. Welke (2011: 122)), also um die im Sprachgebrauch verankerte(n) Bedeutung(en) eines Verbs.

Aus Erwerbsperspektive schreibt Tomasello (1999: 134) diesbezüglich, dass uns erst das Wissen um die im Verb angelegten Ergänzungen die Bedeutung eines Verbs erfassen lasse. So werde das Verb geben ausgehend von seinen Ergänzungen verstanden: ein Gebender als erste Ergänzung, ein Empfänger als zweite und etwas, das gegeben wird, als dritte Ergänzung. Was trivial scheint, ist auch praktisch von unmittelbarer Bedeutung. Feilke (2013: 114-115) führt die Probleme von Kindern einer 5. Klasse auf, die eine Bildgeschichte beschreiben und erklären sollten, worin ihr Witz bestehe. Die Schwierigkeit bestand vor allem darin, die Bedeutung von etwas besteht in etwas zu erfassen. Anders als etwas besteht aus etwas erfordert das bildungssprachliche Verb bzw. Valenzmuster eine Analyse: der Referent der meist abstrakten ersten Ergänzung wird in der zweiten Ergänzung als Inhalt der ersten erklärt. ${ }^{30}$

Die Valenzidee wirkt auf den ersten Blick relativ einfach. Das eingängige Bild vom Drama, seinen Mitspielern und den Umständen bietet einen intuitiven Zugang. Zudem findet die Valenztheorie u.a. erfolgreiche Anwendung im DaF-Unterricht. Aus diesen Gründen, dem erklärenden und praktischen Potential, ist es gerade in der Lehrerausbildung wichtig, ein differenziertes Valenzverständnis zu vermitteln. Ansonsten besteht die Gefahr einer Simplifizierung, die wirkliches Verständnis von funktionaler und formaler Strukturbildung verstellt. Daher wird im Folgenden eine kurze Übersicht über funktionale und formale Valenzrelationen gegeben. ${ }^{31}$

30 Sicher braucht ein Schüler jenes Valenzwissen für sein eigenes Tun nicht explizit. Dafür genügt die Erfahrung mit Homonymen innerhalb entsprechender Zusammenhänge. Zukünftige Lehrer sollten wissen, was dahinter steckt.

31 Da es hier nicht um die Reflektion theoretischer Kontroversen geht, werde ich diese auslassen, verweise aber auf Jacobs (1994), Ágel (2000) und Welke (2011). 
Der funktionale Unterschied zwischen Angaben und Ergänzungen besteht darin, dass Ergänzungen stark, ja existentiell im Verb angelegte Merkmale erfüllen (determinieren). ${ }^{32}$ Existentiell sind jene Merkmale in Bezug auf das Ereignis, welches durch das Verb konstruiert wird. In Bezug auf das bereits erwähnte Verb geben bedeutet dies, dass die sprachliche Konstruktion eines geben-Ereignisses über die existentiellen Merkmale Gebender, Gegebenes und Empfänger verfügt. Durch jene existentielle Relationalität werden funktionale Leerstellen eröffnet, welche von den Ergänzungen gesättigt werden. Dabei handelt es sich primär um das Subjekt und die Objekte. Ein geben-Ereignis verfügt darüber hinaus über unspezifischere (da auf viele andere Ereignisse auch zutreffende) Merkmale wie Ort, Zeit, Grund etc. Diese können durch Angaben, die klassischen Adverbiale ausbuchstabiert werden.

Im Gegensatz zur Merkmalsübertragung von den Ergänzungen und Angaben zum Verb verläuft die formale Abhängigkeitsrelation (Dependenz) vom Verb zu den Ergänzungen und Angaben. Ergänzungen hängen jedoch anders vom Verb ab als die Angaben. Hierauf zielt der Valenzbegriff ab. Denn das Verb übe gleich einem Atom, so Tesnière (1959: 238, § 3), eine ganz bestimmte Anziehungskraft auf eine festgelegte Zahl von Ergänzungen aus. Bildlich schreibt er von einem mit Häkchen ausgestatteten Atom, welches, je nach Zahl der Häkchen, eine ganz bestimmte Zahl von Ergänzungen in Abhängigkeit halte. Die Anzahl der Häkchen bildet die Valenz eines Verbs. Die vom ersten Häkchen abhängige Ergänzung ist das Subjekt. Die von den weiteren Häkchen abhängigen Ergänzungen sind in erster Linie die traditionellen Objekte. Bereits Tesnière (1959: 238-239, § 5) weist darauf hin, das nicht alle Valenzen belegt bzw. gesättigt werden müssen.

Der Richtung der Abhängigkeitsrelation vom Verb zu den Ergänzungen entspricht die Zuweisung semantischer Rollen vom Verb an die Ergänzungen. Um existentiell angelegte Werte zu sättigen, erhalten die Ergänzungen jeweils verschiedene Rollen. Sie werden als verschiedene Mitspieler eines Ereignisses zueinander in Beziehung gesetzt. Das Prädikat prädiziert über den Ergänzungen, indem es ihnen jene Rollen zuweist. ${ }^{33}$ So ist in dem Satz Sie gibt ihm das Buch eben sie die Gebende, ihm der Empfänger und das Buch das Gegebene. Die Rol-

32 Die funktionale Kehrseite der formalen Abhängigkeit beschreibt Tesnière (1959: 42, § 3) als nur theoretisch voneinander getrennte Ebenen. Tatsächlich drücke die strukturelle Abhängigkeitsrelation die semantische Merkmalsübertragung aus. Diese Grundannahme wird in funktional ausgerichteten Grammatiken wie bei Welke (2007) und Welke (2011) ausgebaut.

33 Diese Funktion wird in der Literatur als logische Argumenthaftigkeit (vgl. Jacobs (1994: 17)) bezeichnet. Dies zielt auf die logische Abstraktion des Verbs als Funktion und die der Ergänzungen als Argumente der Funktion ab. Welke (2011: 65) definiert die Prädikation als Bestimmungsrelation wie folgt: „das Zeichen $\mathrm{x}$ bestimmt das Zeichen $\mathrm{y}$ dann und nur dann, wenn $\mathrm{x}$ eine Beschaffenheit bedeutet, die dem von y Bedeuteten zukommt.“ 
lenzuweisung ist ein wichtiges Indiz für die Bestimmung einer Einheit als Ergänzung. Denn Angaben drücken selbst ihre Rolle aus und prädizieren somit über das Verb oder den Satz. In Sie gibt ihm das Buch im Garten findet das Geben-Ereignis an einem Ort statt, nämlich im Garten. ${ }^{34}$

In der gleichen Richtung, in der die Abhängigkeit und die Prädikation verlaufen, geschieht auch die Festlegung formaler Eigenschaften der Ergänzungen durch das Verb. Daher regiert das Verb seine Ergänzungen formal. Die klassischen Objekte erhalten als nominale Ergänzungen des Verbs primär die formalen Merkmale zum Ausdruck der Kategorien Akkusativ, Dativ und/oder eine Präposition mit entsprechender Kasusrektion. Die Verbform gibt regiert z. B. den Nominativ bezüglich der ersten Ergänzung, den Dativ bezüglich der zweiten und den Akkusativ bezüglich der dritten Ergänzung. ${ }^{35}$ Im nicht mehr produktiven Randbereich

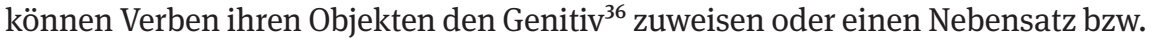
eine Infinitivgruppe als Ergänzung verlangen. Alle nicht im Valenzträger angelegten und damit auch nicht von diesem formal regierten Einheiten zählen zu den Angaben. Typische Angaben werden durch Adverbiale ausgedrückt. Denn sie drücken Umstände von Ereignissen aus, kontextualisieren das Tesnière'sche Drama.

Es gibt aber auch Verben, die wie sich befinden, dauern oder sich benehmen eine klassischerweise als Adverbial bezeichnete Lokal- bzw. Temporal- oder Modalergänzung brauchen. Hier muss der Wert des Adverbialbegriffes für die schulgrammatische Satzanalyse hinterfragt werden. Wenn, wie hier vorgeschlagen, die Satzanalyse auf valenzielle Füße gestellt werden soll, dann sollte der Adverbialbegriff auf Angaben beschränkt werden. Dieser zielt ohnehin primär auf semantische Kontextualisierungsfunktionen ab. Der Gießener Kreis verzichtet in seinem Verzeichnis schulgrammatischer Terminologie auf jene semantischen Klassifizierungen, die in der Praxis häufig ohnehin in der Modalklasse als einer Art „Papierkorb“ enden, wie Welke (2007: 158) schreibt. In Bezug auf die Adverbialproblematik ist interessant, dass es bei Becker (1837) noch kein Adverbial als Satzglied gibt. Ohne einen klaren Valenzbegriff unterscheidet Becker (1837: 112-113, $\S 237)$ die „objektiven Satzverhältnisse“ in die „ergänzenden“ auf der einen und die nicht-ergänzenden, „bestimmenden“ auf der anderen Seite. Letztere zielen

34 Natürlich prädiziert das verbale Prädikat auch über die Angabe, so dass der Ort „im Garten“ hier eben zu einem Ort wird, an dem ein Geben-Ereignis stattfindet.

35 Diese Reihenfolge ergibt sich durch Abzählung: Gestern hat sie ihm $_{2}$ das Buch ${ }_{3}$ gegeben.

36 Die Schulgrammatik soll, wenn möglich, funktionale Erklärungen bieten. Daher kann mit Wurzel (1994: 71-74) der Rückgang des Genitivobjekts als Abbau eines markierten, weil seltenen Valenztyps (Nominativ-Genitiv/Nominativ-Akkusativ-Genitiv) erklärt werden. Die Voraussetzung dafür war, dass der Genitiv als Objektkasus seine eigene semantische aspektuell-partitive Leistung verloren hat. 
auf die Angaben ab. Bei Verben der Bewegung und des „Aufenthaltes“ realisieren Richtungs- und Ortsausdrücke nach Becker (1837: 117) das ergänzende objektive Verhältnis. ${ }^{37}$ Erst in der Verknappung der Becker'schen Grammatik durch Wurst (1867: 47) taucht anstelle des bestimmenden Verhältnisses das „Adverbiale“ bzw. der „Umstand“ als eines von fünf Satzgliedern auf. Zwar erwähnt Wurst (1867: 34, $\S 13)$, dass Orts- und Richtungsausdrücke notwendig sein können, klassifiziert sie aber semantisch einheitlich unter den Umständen, also unter den Adverbialen. Diese Klassifizierung führt jedoch zu keinerlei Einsicht, außer der, dass in dem Satz Paul befindet sich im Zimmer die PP im Zimmer einen Ort bezeichnet. Hierfür braucht es aber keine Grammatik. Grammatisch interessant ist, dass Adverbiale nicht valenzgebunden sind und den Inhalt von Sätzen situieren oder modifizieren. Dies geschieht formal äußerst vielfältig, nämlich durch Adverb-, Präpositional-, Adjektiv- und Nominalgruppen sowie durch Nebensätze. Sofern es möglich ist, spricht nichts gegen die weitere semantische Differenzierung. Nur sollte sie nicht voreilig Unterschiede anstelle relationaler Gemeinsamkeiten beleuchten. Unter dieser Voraussetzung können die semantisch und formal sehr vielfältigen Averbiale als ein wichtiges Tor zum grammatischen Lernen gesehen werden.

In Anlehnung an Zifonun et al. (1997: 1101) schlage ich für die angesprochenen lokalen, modalen und temporalen Ergänzungen den Begriff Situativergänzung für die Satzanalyse vor. Damit wird der Adverbialbegriff eindeutig auf Angaben beschränkt. „Hybridbezeichnungen“, wie Eisenberg (2006: 259) notwendige Adverbiale oder Umstandsergänzung usw. nennt, werden somit vermieden. Die Besonderheit der Situativergänzungen liegt darin, dass sie verbale Valenzstellen sättigen, aber nicht subkategorisierend sind bzw. dass keine verbspezifische Rektion nachgewiesen werden kann. Systematisch (nicht in Bezug auf einzelne Verben) betrachtet, handelt es sich um untypische Ergänzungen, was der Begriff Situativergänzung erfassen soll.

Testen lässt sich Rektion, indem gefragt wird, ob die konkrete Form der fraglichen Einheit vom Verb vergeben wird oder nicht (Warum heißt es Ich helfe dir? Weil helfen den Dativ regiert.) Umgekehrt kann die Subklassenspezifik als Folge der Rektionsbeziehung getestet werden. Dabei geht es um die Frage, ob die entsprechende Form von einem bestimmten Verb oder einer bestimmten Verbgruppe regiert wird oder nicht (In Ich helfe dir können anstelle von helfe Verbformen wie gratuliere, glaube, folge aber nicht sehe oder schlafe stehen). Auf diese Weise wird das Subjekt als erste verbale Ergänzung im Nominativ ,auffällig‘. Da bis auf wenige Ausnahmen (mir/mich graut davor) alle aktivisch gebrauchten finiten Verben mit ihrer ersten Ergänzung im Nominativ gebraucht werden, kann nicht

37 Auch Sütterlin (1907: 345-346, § 367) will auf den Adverbialbegriff verzichten und schreibt von notwendigen im Gegensatz zu entbehrlichen Ergänzungen. 
von Subklassenspezifik gesprochen werden. Eine plausible Erklärung ist, dass die meisten aktivisch gebrauchten finiten Verben eben per Default ihrem ersten Argument den Nominativ zuweisen, diesen also regieren, obwohl sich hieraus keine Spezifik in Bezug auf den jeweiligen Valenzträger ergibt. Dies schlägt Eisenberg (2006: 53) unter dem Begriff der kategorialen Rektion vor.

Insbesondere der Test der Subklassenspezifik erlaubt Einblick in die Tatsache, dass verschiedene Verben die gleichen Kasus regieren und somit Subklassen bilden. Jene Verallgemeinerungen werden traditionell unter dem Stichwort Satzbauplan wie in der Duden Grammatik (2016: 916, 1444) erfasst. Die Verbform gibt vergibt an ihre erste Ergänzung, den Gebenden, den Nominativ. Dieses Rektionsverhältnis liegt jedoch, wie erwähnt, bei fast allen Verben vor. Der Nominativ kodiert zwar bei gibt den Gebenden, aber auch bei liegt eine liegende Entität und bei wachsen eine Entität, an der sich Wachstum vollzieht. Auf den ersten Blick lässt sich das nicht über die Semantik erklären. Einmal handelt es sich um ein Agens (Handlungsträger), einmal um einen Zustands- und dann wieder um einen Vorgangsträger. Bereits Tesnière (1959: 108, § 3) unterscheidet die Ergänzungen primär nach ihrer Zahl in einen ersten, zweiten und dritten Mitspieler. Welke (1988: 217) baut den Unterschied in der Reihenfolge zu einem perspektivischen (logisch-pragmatischen) Rollenkonzept aus. Danach markiert der Nominativ eben die erste in der Verbvalenz angelegte Ergänzung als Ausgangspunkt der Ereignisdarstellung.

Insbesondere für die Schulgrammatik sollte das Konzept signifikativ-semantischer Rollen, maßgeblich von Klaus Welke ${ }^{38}$ entwickelt, nutzbar gemacht werden. Signifikative Rollen zielen auf die einzelsprachliche Bedeutung und den einzelsprachlichen Kontrast ab, nicht auf die Bezeichnung (Welt). Sie zielen auf Form-Funktions-Zusammenhänge in gegebenen Äußerungen ab und nicht auf angeblich bedeutungsstabile Ableitungen eines Satzes aus einem anderen. Das wird besonders bei der Betrachtung des Passivs deutlich. Wird von einem entsprechenden Ereignis in der Welt (onomasiologisch) ausgegangen, so sind ein Aktivsatz wie Anna streicht den Zaun und ein Passivsatz wie Der Zaun wird gestrichen bezeichnungsgleich (Konverse). Somit wären die Satzglieder nur mehr rein formal bestimmbar. Denn obwohl sich die Satzgliedfunktionen verändern, bleibt der Zaun als Objekt im Aktivsatz und als Subjekt im Passivsatz der Handlungsgegenstand. Wird die gegebene sprachliche Struktur ernst genommen und semasiologisch vorgegangen, so findet mit der Veränderung des Prädikats von streicht zu wird gestrichen auch eine Veränderung des Geschehenstyps und damit der semantischen Rollen statt, die wiederum Satzgliedfunktionen entsprechen.

38 Cf. Welke (1988), Welke (2005) und Welke (2019). Auch die Grammatische Textanalyse von Ágel (2017) ist signifikativ-semantisch fundiert. 
Der Satzbaubplan aus Subjekt und Objekt, welchen das Prädikat streicht aufruft, drückt eine Handlung mit einem Handlungsträger (Agens) und mit einem Handlungsgegenstand (Patiens) aus. Der einstellige Satzbauplan, welcher unter anderem von Passivprädikaten wie wird gestrichen aufgerufen wird, bedeutet einen Vorgang mit dem Subjekt als Vorgangsträger. Der Aktiv- und der Passivsatz konstruieren verschiedene Bedeutungen im Sinne von verschiedenen Perspektiven auf Ereignisse. Sie sind nicht auseinander abgeleitet. Bestimmte Werte der Grundvalenz werden in abgewandelter Form und Bedeutung an die PassivStruktur vererbt.

Eine Bedingung für die signifikativ-semantische Analyse von Satzgliedern ist ihre prototypische anstelle einer invarianten Bestimmung. ${ }^{39}$ In Sätzen wie Anna streicht den Zaun und Anna liebt den Sonnenuntergang trägt Anna als Subjekt des Subjekt-Akkusativobjekt-Bauplans die Bedeutung Handlungsträger. Der Zaun und der Sonnenuntergang bekommen die Rollenbedeutung Handlungsgegenstand. Eine solche Abstraktion findet sich auch im Wortschatz. So wie wir nicht allen Dingen in der Welt einen Eigennamen geben, sondern über Appellativa verfügen, so kodiert die Grammatik auch die Streichende nicht anders als die (weniger prototypisch handelnde) Liebende. ${ }^{40}$

In der Fachliteratur wird meist als erstes, aber weder einziges noch notwendiges, sondern nur hinreichendes Kriterium zur Bestimmung von Ergänzungen ihre Notwendigkeit, d.h. ihre Nicht-Weglassbarkeit besprochen. ${ }^{41}$ Tatsächlich wäre es einfach, wenn die Valenzstellen auch obligatorisch zu sättigen wären. Dies ist aber nicht so. Obligatheit liegt z. B. bei der ersten Ergänzung, dem Subjekt von aktivischen finiten Verben vor. Dennoch sind Situationsellipsen möglich (Freut mich). Ebenso sind Ergänzungen von Präfix- und Partikelverben i.d.R. obligatorisch. ${ }^{42}$ Die Ausbeute des Tests ist also recht gering, wenn bedacht wird, dass Subjekte über das Kriterium der kategorialen Rektion und die Mehrheit der Objekt-Ergänzungen von Präfix- und Partikelverben über lexikalische Rektion

39 Im Sinne der Proto-Rollen von Dowty (1991).

40 Wie ertragreich die prototypisch, signifikativ-semantische Analyse ist, zeigt Höllein (2019) in Bezug auf viele Präpositionalobjekte, die traditionell rein formal bestimmt werden. So ermittelt Höllein (2019: 162, 178-180) konventionalisierte Satzbaupläne, in denen Präpositionalobjekte zum Ausdruck einer signifikativ-semantischen Rolle gebraucht werden. Teilweise bilden sich produktive Nischen, in denen die traditionell als fixiert und semantisch entleert geltenden Präpositionalobjekte mit neuen Verben gebraucht werden: so z.B. auf bei Handlungsausdrücken wie auf etw. hoffen/warten/spekulieren und als produktive Bildungen in auf etw. trainieren/lernen. Das Präpositionalobjekt mit auf drückt die Rolle von etwas Zukünftigem (Prospectum) aus. 41 Cf. Helbig (1992a: 74), Jacobs (1994: 14).

42 Bei Präfix- und Partikelverben liegt ein stärkerer formaler Zwang zum Ausdruck der Ergänzung vor, weil entsprechende Präverbkonstruktionen den Ausdruck der Ergänzungen erzwingen, welche sie in die Valenz einbringen bzw. deren lexikalischer Ankerpunkt sie sind. 
ermittelt werden können. Zudem stellt, wie Ágel (2000: 174-175) zeigt, der Test in zweifacher Hinsicht ein methodisches Problem dar. Erstens müssten die Testbedingungen stabil gehalten werden (Textsorte, Mündlichkeit vs. Schriftlichkeit, isolierte oder kontextuelle Betrachtung etc.) und zweitens funktioniert der Test nur vor dem Hintergrund eines theoretischen Begriffes von Ungrammatikalität. Diese Probleme spiegeln sich direkt in sehr uneinheitlichen Bewertungen der Tests durch Studenten wieder. In der Lehre zeigt sich außerdem ein didaktisches Problem, nämlich dass Studenten trotz aller ,Warnungen' die Valenz von Verben auf die Obligatheit der Ergänzungen reduzieren. ${ }^{43}$ Die Verlockung scheint also groß zu sein, jenes scheinbar einfache, aber höchst problematische Kriterium zur Grundlage des Valenzbegriffes zu machen und somit Valenz nicht wirklich zu erfassen. Daher sollte in der akademischen Schulgrammatik Nicht-Weglassbarkeit nur dann eine Rolle spielen, wenn weder Rollenzuweisung noch Rektion und Subklassenspezifik nachgewiesen werden können, die Wortgruppe aber dennoch als notwendige Ergänzung erscheint. ${ }^{44}$ Viel eher sollten die situativen und/oder kontextuellen und/oder strukturellen Bedingungen von Nicht-Realisierung thematisiert werden, was kurz aufgezeigt wird.

Sehr allgemein kann beobachtet werden, dass bestimmte Ergänzungen umso eher nicht realisiert werden, je spezifischer die Verbbedeutung ist. ${ }^{45}$ Mit anderen Worten: je vorstellbarer das entsprechende Ereignis auch ohne die sprachlich realisierte Ergänzung ist, umso eher kann sie nicht realisiert werden. Das wird beim Vergleich vom spezifischeren Positionsverb liegen in (1a) mit dem eher unspezifischen sich befinden in (1b) deutlich.
(1) a. Paul liegt.
b. *Paul befindet sich.

Dennoch eröffnet liegen genauso wie sich befinden die entsprechende Valenzstelle für eine Lokalrelation. Es muss also mit Pasch (1977: 22) zwischen Valenz als Möglichkeit und Ergänzungsbedürftigkeit als Notwendigkeit unterschieden werden.

43 Welke (2011: 48) macht in einer Fußnote auf die gleiche Beobachtung aufmerksam.

44 Granzow-Emden (2014: 31) lehnt den Test ebenfalls ab, bespricht ihn aber als erste, eben schlechte und einzige formale Probe zur Unterscheidung der Ergänzungen von Angaben. Welke (2011: 53) schlägt eine disjunkte, prototypische Auswertung zweier Tests vor, wonach Ergänzungen regiert (subklassenspezifisch) und/oder obligatorisch seien. Die Idee jener prototypischen Bestimmung durch die disjunkte Verbindung von Notwendigkeit und/oder formale Spezifizität stammt von Jacobs (1994: 65).

45 Cf. Heidolph et al. (1981: 426), Welke (2011: 137). 
Bei vielen zweiwertigen Verben kann die zweite Ergänzung im Akkusativ, Dativ oder mit einer Präposition, bei dreiwertigen die zweite Ergänzung im Dativ unrealisiert bleiben. Dabei kann es sich um eine kontextuell motivierte NichtRealisierung handeln, da entsprechende Ergänzung bereits genannt wurde. Das ist der Fall bei der nicht-realisierten zweiten Ergänzung von unterschrieb in (2). Das zu unterschreibende Dokument wurde bereits im Vortext erwähnt.

(2) Auf Geheiß von Strauß mußte Stoiber von allen Ministern und Staatssekretären eidesstattliche Erklärungen einholen [...] Nur einer blieb standhaft und unterschrieb nicht: der Kultusminister Hans Maier. ${ }^{46}$

Nicht-realisierte Ergänzungen können ebenso indefinit mitverstanden werden. Das vom Verb bezeichnete Geschehen steht im Fokus. Hierin liegt eine wesentliche Funktion jener Nicht-Realisierung, wie der folgende Beleg in (3) zeigt.

(3) Wie können die Leute, die hier leben, [...] so barbarisch geworden sein, dass sie umbrachten, ermordeten, verhungern ließen, akribische Versuche an Menschen durchführten und sie zu Tode quälten? ${ }^{47}$

Diejenigen, die sie umbrachten, ermordeten und verhungern ließen werden nicht ausgedrückt. Die Verben entwerfen mit ihrer zweiwertigen Grundvalenz Handlungen, die zu konkreten Resultaten führen. Durch das Ausblenden der jeweils zweiten Ergänzungen (Valenzreduktion) werden Tätigkeiten dargestellt. Der Unterschied ist nur signifikativ-semantisch zu erfassen. Als Test schlägt Pasch (1977: 23-24) die intransitive Antwortmöglichkeit auf die Frage Was tut er gerade? bzw. Was ist gerade mit ihm? vor.

Die Nicht-Realisierung der zweiten Ergänzung kann einhergehen mit einer charakterisierenden Lesart der ersten Ergänzung wie in (4). Hier geht es um Anna Seghers als schreibende Frau bzw. als Schriftstellerin. Die sprachliche Bedeutung ist Klassenzuweisung und nicht Handlung.

(4) Anna Seghers schreibt und ist Mutter. ${ }^{48}$

Pasch (1977: 23-24) zeigt, dass Kontrastkonstruktionen des Musters nicht x-en, sondern y-en dazu führen können, dass selbst als obligatorisch eingestufte Ergän-

46 Süddeutsche Zeitung, 16.01.1999, S. 9.

47 Uwe Timm: Ikarien. Köln, Kiepenheur \& Witsch, 2017, S. 320.

48 Aus Argonautenschiff. 12. Jahrbuch der Anna-Seghers-Gesellschaft Berlin und Mainz. Berlin, Aufbau, 2003, S. 41. 
zungen wie die zweiten Ergänzungen von begrüßt, schlägt vor, berät und begleitet in (5a) nicht realisiert werden (5b). Hier wird ein ,pures' Tun im Allgemeinen (keine Handlung) ausgedrückt. Es geht nicht um konkrete Ereignisse, in denen jemand begrüßt, beraten oder begleitet wird. Auch hier wird die Tragweite einer signifikativ-semantischen Analyse deutlich.

(5) a. *Paul begrüßt/schlägt vor/berät/begleitet.

b. Il Patrono ist auf seine Art einmalig, er begrüßt nicht, sondern er empfängt, er schlägt nicht vor, sondern er berät, er ist nicht da, sondern er begleitet durch den Abend. ${ }^{49}$

Ähnlich kann die Nicht-Realisierung der zweiten Ergänzung motiviert sein in einer Modalverb-Konstruktion, wenn es wie im fünften Gebot (6) um eine potentielle Töten-Situation als Tätigkeit geht.

(6) Du sollst nicht töten..$^{50}$

Bei manchen Verben muss trotz ihres Gebrauchs in der Kontrastkonstruktion oder beim potentiellem Gebrauch mit Modalverb das zweite Argument realisiert werden ( ${ }^{\star}$ er befindet sich nicht, sondern lebt). Deshalb differenziert Pasch (1977: 23) zwischen absolut und relativ obligatorischen Ergänzungen.

Um absolute Obligatheit handelt es sich bei der zweiten Ergänzung des viel besprochenen Verbs „sich befinden“.51 In einem Satz wie „Paul befindet sich hier“ fallen in Bezug auf „hier“ die Tests für Regiertheit und Subklassenspezifik negativ aus. Ebenso bringt „hier“ die abstrakte Rolle Ort bereits mit, so dass sich diese nicht als vom Verb zugewiesen nachweisen lässt. Aber eine Sich-BefindenSituation hat als existentielles Merkmal einen Ort als mitspielende Größe. Semantisch handelt es sich um eine typische Ergänzung, wenn wir Orte genauso wie Dinge und Personen als Entitäten verstehen. Die Besonderheit liegt darin, dass eine von der semantischen Valenz als Ort geforderte Größe formal nicht vom Verb regiert wird und auch nicht subklassenspezifisch ist. Aus diesem Grund handelt es sich syntaktisch (formal) um eine atypische Ergänzung. Für diese wurde der Begriff der Situativergänzung vorgeschlagen.

49 https://www.tripadvisor.de/ShowUserReviews-g198442-d6640767-r311258859-Il_BrunelloErding_Upper_Bavaria_Bavaria.html (22.06.19).

50 2. Buch Mose (Exodus) 20:13.

51 U. a. bei Âgel (2000: 176) in Bezug auf „sich aufhalten“, Welke (2011: 87) und außerhalb der Valenztheorie bei Müller (2010: 24). 
Welke (2011: 85-88) bespricht Fälle, in denen sich schwer entscheiden lässt, ob es sich um eine Ergänzung oder Angabe handelt (von-Phrase beim Passiv, für- sowie instrumentale wie commitative mit-Phrasen). Denn Rektion und Subklassenspezifik lassen sich nicht klar nachweisen und die Frage nach der existentiellen Merkmalshaftigkeit wird spekulativ. ${ }^{52}$ Es geht hier nicht um jene Fälle im Einzelnen. Wesentlich ist, hierauf weist auch Welke (2011: 60) hin, entsprechende Tests als $\mathrm{zu}$ interpretierende Indizien $\mathrm{zu}$ verwenden, nicht als Nachweise oder Definitionen.

Die Schulgrammatik sollte keine Angst vor offenen Fragen in der Fachwissenschaft bzw. vor Kategorien im Übergang (von Angaben zu Ergänzungen) haben. Denn erst die Diskussion um unklare Fälle weckt (freilich nach Behandlung der klaren) Interesse und bezieht die Studenten in die lebendige Suche nach Antworten ein.

Ausgehend vom Prädikat als verbalem Valenzträger ist nun zu diskutieren, welche Satzglieder in einer reformierten Schulgrammatik anzusetzen sind. Die vier grundlegenden Satzglieder Subjekt, Objekt, Prädikativ, Adverbial werden in der Duden Grammatik (2016: 793-794) unterschieden. Ágel (2017: 43) schlägt zusätzlich ein Kommentarglied vor, welches der Gießener Kreis übernommen hat. Die Duden Grammatik (2016: 794) führt unter den Adverbialen auch Kommentaradverbiale auf. Bei diesen handelt es sich um frei hinzufügbare Glieder, welche die Einstellung des Sprechers zu dem dargestellten Sachverhalt ausdrücken. Welke (2007: 1, 145-150) nimmt als Ergänzung ein weiteres „Satzglied [...] in den Kanon“ auf, das Direktivum. Hierbei handelt es sich um in der Verbvalenz angelegte Richtungsergänzungen. Ihr Ausdruck ist nur indirekt bei den sogenannten Wechselpräpositionen durch Festlegung auf den Akkusativ vom Verb regiert. ${ }^{53}$ Die Präposition ist anders als bei Präpositionalobjekten nicht vom Verb regiert. In der traditionellen Grammatik, auch in der Duden Grammatik (2016: 795) werden sie zu den Lokaladverbialen gezählt, was dem Valenzbegriff entgegensteht. Daher

52 Ein Lösungsansatz wäre, entsprechende mit- und für-Phrasen als klassische Angaben zu analysieren, welche jedoch bei einzelnen Verben den Charakter von Ergänzungen im Sinne von existentiellen Merkmalen und Assoziiertheit u. a. durch kollokationale Einschleifung bekommen. In diesem Sinne müsste die commitative Angaben-Konstruktion mit jemandem bei telefonieren als Ergänzung gewertet werden, ebenso bei schlafen, wo zudem Lexikalisierung vorliegt. In Bezug auf kochen bei mit jemandem kochen handelte es sich weiterhin um eine Angabe. Dies entspricht dem von Ágel (2000: 180-182) diskutierten Kriterium abgestufter Vorhersagbarkeit. Die vonPhrase beim Passiv stellt eine Erweiterung der Passivstruktur dar, weshalb Weinrich (2003: 167) vom erweiterten Passiv schreibt. Mit Ágel (2017: 277) sollte es als dynamisches Präpositionalobjekt bestimmt werden.

53 Der Begriff Wechselpräposition ist irreführend. Denn die beiden Varianten wechseln sich ja gerade nicht ab, sondern drücken verschiedene Konzepte aus. 
sollte das Direktivum als verbale Ergänzung in die Terminologie einer reformierten Schulgrammatik aufgenommen werden. Somit sollte in einer reformierten Schulgrammatik zwischen Präpositionalobjekten, Direktiva und Situativergänzungen als Ergänzungen sowie zwischen Adverbialen und Kommentargliedern als Angaben unterschieden werden.

\subsection{Wortgruppen und Attribute}

Die andere Betrachtungsebene betrifft die Teil-Ganzes-Beziehung (Konstituenz) und die lineare Anordnung der einzelnen Teile einer gegebenen größeren Einheit. Auf Satzebene werden die Satzkonstituenten (Satzglieder) durch die bekannten Glinz'schen Proben - durch experimentierende Verfahren, wie Glinz (1952: 58) schreibt - ermittelt. Aus didaktischer und linguistischer Sicht wird immer wieder betont, wie wichtig die eigenständige Ermittlung grammatischer Einheiten ist. ${ }^{54}$ Primus (2015: 83, 85) warnt aber zu Recht davor, dass in der Anwendung jener Proben noch kein Wert an sich liegt. Erst wer weiß, dass es nur vom Prädikat ausgehend überhaupt Satzglieder gibt, sei auf der „richtige[n] Spur“. Denn verschiebbar und erfragbar ist typischerweise, was als Ergänzung oder Angabe direkt vom Verb abhängt und deshalb Satzglied ist. ${ }^{55}$

Für ein grundlegendes grammatisches Verständnis bietet sich die Analyse von Sätzen an, die neben einer primären auch eine weitere Interpretation erlauben, wobei beide Lesarten auf jeweils unterschiedlichen strukturellen Einbettungen basieren. Dies ist der Fall bei der folgenden Überschrift (7).

\section{(7) Polizei jagt Verbrecher mit Oldtimer. ${ }^{56}$}

Am Bau und den Rektionsverhältnissen innerhalb der Präpositionalgruppe mit Oldtimer ändert sich nichts, nur an ihrer Verankerung. Die Präpositionalgruppe kann als Adverbial direkt dem Prädikat untergeordnet sein jagt mit Oldtimer. Möglich ist jedoch auch ihre Einbettung in Verbrecher, ihr Gebrauch also als Attribut in Verbrecher mit Oldtimer. Somit kann Einsicht in das grundlegende syntaktische Prinzip der Einbettung von Bestandteilen (Konstituenten) in größere Bestandteile (Konstituenten) gewonnen werden. In diesem Fall entspricht der unterschiedlichen Einbettung auch eine jeweils andere Interpreta-

54 Cf. u. a.Eisenberg (2004: 11), Granzow-Emden (2014: 15) und in Bezug auf den Zweitspracherwerb Housen et al. (2005: 238).

55 Eine gute Übersicht über den Status der Tests bietet Müller (2010: 7-11).

56 Die Welt, 16.09.2007. 
tion, wodurch der Zusammenhang zwischen Form und Funktion deutlich wird. Trotz unterschiedlicher funktionalgrammatischer Einbettung, einmal als Satzglied und einmal als Wortgruppenglied, drückt die Präpositionalgruppe hier auf ähnliche Weise ein Instrument aus. Ágel (2017: 35, 55) bezeichnet die Identität auf verschiedenen Funktionsebenen als „Recycling“ und schreibt: „Analoge semantische Werte [...] werden vertikal - hierarchisch - durch die funktionalen Ebenen grammatisch ,durchgereicht““. Der primäre Satzgliedwert bekommt rekursiv als Argument der Wortgruppenfunktion Attribut den Wert Instrument-Attribut. Interessanterweise liegt bereits in der Schulgrammatik von Sütterlin (1907: 328) ein wesentlicher Fokus auf jenen „Verschiebungen der Glieder“ (beispielsweise zur Erklärung des possessiven Dativattributs in dem Kaufmann sein Haus).

Attribut und Satzglied sind relationale Funktionsbegriffe und erlauben daher keinen Einblick in den Bau der entsprechenden Wortgruppe. ${ }^{57}$ Wie bereits erwähnt, verfügte das Verzeichnis der Kultusministerkonferenz (1982) jedoch nicht über ein Konzept der Wortgruppe. Der Grund hierfür liegt neben der Satz(funktions)zentriertheit m. E. darin, dass ein primär deskriptiver allgemeiner Wortgruppenbegriff (im Gegensatz z. B. zum Phrasenbegriff in der $x$-bar-Theorie) kaum sinnvoll ist. Mit dem Attributbegriff ${ }^{58}$ wird zwischen Erweiterungen des Verbs und des Substantivs (ebenso des Adjektivs und des Adverbs) kategorial unterschieden, was in modernen Theorien zu Gunsten maximaler Generalisierung nicht gemacht wird. ${ }^{59}$ Da Attribute nur in Wortgruppen vorkommen, muss der Wortgruppenbegriff geschärft werden, was im Folgenden skizziert wird.

Als primäre Grundlage der Satzstruktur wurde die direkte Abhängigkeit der Satzglieder vom Verb besprochen. Tesnière (1959: 13, § 2) schreibt verallgemeinernd vom regierenden Element (régissant/Regens) und einem abhängigen Element (subordonné/Dependens). Diese Dependenzrelation sieht Tesnière (1959: 45, § 13) in „mikroskopischer Vergrößerung“ auch in komplexen regierenden Elementen. Diese bezeichnet Tesnière (1959: 47, § 6) als Kern (Nukleus), welcher aus zwei Elementen besteht: aus einem strukturellen Zentrum und einem semantischen Zentrum. Beide Zentren bilden den Kern wie bei den zusammengesetzten Zeitformen analytisch (hat...gemacht) oder synthetisch (machte). Eisenberg (2006: 52-54) entwickelt in Anlehnung an morphologische Kerne

57 Ganz praktisch wird jener Einblick auch zum Erwerb der satzinternen Großschreibung gebraucht. Röber (2011: 310) nutzt Adjektivattribute zur Identifizierung des nominalen Kerns. Das Konzept stammt aus den 1980er Jahren. Eine praktische Anwendung im Unterricht demonstrieren Günther und Nünke (2005).

58 In die Schulgrammatik bringt Becker (1845: 248) den Begriff. Fuhrhop und Thieroff (2005: 308-315, 325) geben eine Übersicht über die Entwicklung des Attributbegriffs in neueren Grammatiken.

59 Cf. Welke (2016: 59, 63). 
und Köpfe ein ähnliches, allerdings nur auf die analytischen Formen bezogenes Konzept und bezeichnet das strukturelle Zentrum im Vorbereich als Kopf, das semantische im Nachbereich als Kern. Die syntaktische Beziehung zwischen beiden besteht darin, dass der Kern an den Kopf gebunden ist. Ágel (2017: 697) übernimmt dieses Konzept und die Terminologie, wendet es aber auch auf die synthetischen Formen an. Da die Begriffe Kopf und Kern häufig gleichbedeutend benutzt werden und der Kernbegriff auch nicht dem Nukleus von Tesnière (1959) entspricht, werde ich weiter von einem strukturellen und einem semantischen Zentrum schreiben. Mein Vorschlag ist, den allgemeinen Wortgruppenbegriff in eine Gruppe im engsten Sinne, den Wortkomplex und dessen Erweiterung, eine Wortgruppe im weiteren Sinne zu untergliedern. ${ }^{60} \mathrm{Zu}$ den Wortkomplexen gehören u.a. analytische Verbkomplexe aus Hilfsverb als strukturellem und Vollverb als semantischem Zentrum. Als „Analogon“ dazu beschreibt Weinrich (2003: 355356) den analytischen Substantivkomplex aus Artikelwort und Substantiv. So wie die Teile des Verbkomplexes in Verberst- und Verbzweitsätzen eine Klammer (und somit Felder) bilden, so bilden auch das Artikelwort und das Substantiv eine Klammer (und damit Felder). So wie das strukturelle Zentrum des Verbkomplexes die Kategorien Person, Numerus, Tempus, Modus und Genus verbi markiert, das Verb damit eingrenzt (Finitum) und das Subjekt via Kongruenz in die Verbgruppe einbindet, so markiert der Artikel die Kategorien Genus, Kasus (und Numerus) und stellt typischerweise Referenz her. ${ }^{61}$ Ronneberger-Sibold (2010: 95) beschreibt die grundlegende Funktion jener Klammer als „Erleichterung der syntaktischen Dekodierung: Dadurch, dass die jeweils zueinander passenden Klammerränder die Grenzen von (verschieden definierten) Konstituenten klar markieren, weiß der Hörer/Leser während des Dekodierungsprozesses jederzeit, ob er sich am Anfang, im Inneren oder am Ende einer Konstituente befindet.“ Nicht klammerfähig sind die entsprechenden synthetischen Komplexe, nämlich ein finites Vollverb oder zum Beispiel ein artikelloses Substantiv im Plural (Bilder). ${ }^{62}$ Der Ausbau des Verbkomplexes ist, wie weiter oben beschrieben, durch die Valenz des Vollverbs (semantisches Zentrum) vorbestimmt. Sekundär können Angaben hinzugefügt werden. Somit wird der Verbkomplex zur Verbgruppe, maximal zum Satz ausgebaut.

60 Bezüglich des Verbs ist dies üblich, u. a. in Zifonun et al. (1997: 83) und Schäfer (2016: 390). 61 Ágel (1996: 18) schreibt daher auch vom finiten Substantiv. Allerdings macht Ágel (1996: 32) deutlich, dass eine echte syntaktische Nominalklammer nicht aus Artikel und Substantiv, sondern aus dem Flexionsteil, welchen der Artikel trägt, und dem Substantiv besteht, also z. B. da[s-Bild $]$.

62 Eigennamen wie Paul und sogenannte Massennomen wie Gold sind gruppentauglich, ohne komplex zu sein. Personalpronomen zeigen auf ihr semantisches Zentrum, anaphorisch im Text oder deiktisch in der Situation. 
Auch das semantische Zentrum des Substantivkomplexes kann erweitert werden. Hierbei handelt es sich um Attribute. Den Unterschied zu den verbalen Erweiterungen stellt Welke (2016: 65-66) formal und semantisch heraus. Ergänzungen fungieren als Mitspieler des vom Verb ausgedrückten Ereignisses und sind in dessen Valenz enthalten. Die Ergänzungen determinieren die Verbbedeutung. Das Verb prädiziert über seine Ergänzungen, indem es ihnen Rollen zuweist. Attribute charakterisieren primär die Dinge und Verdinglichungen, welche von Substantiven ausgedrückt werden. Wie die Ergänzungen und Angaben vom Verb abhängen, so hängen die Attribute vom Substantiv ab. Aber originäre Attribute sind nicht in der Valenz des Substantivs enthalten und prädizieren über das Substantiv. ${ }^{63}$ Den fundamentalen Unterschied zwischen Verberweiterungen und Substantivattribut beschreibt Welke (2016: 66) vor dem Hintergrund einer „elementare[n] Ontologie“. Der aus Dingen und Beziehungen zwischen den Dingen konzeptualisierten Welt entsprechen das Substantiv bzw. die Substantivgruppe und das Verb bzw. die Verbgruppe in der Sprache. ${ }^{64}$ Wie dargestellt, werden die verbalen Ergänzungen typischerweise durch Substantivgruppen im Nominativ, Akkusativ und Dativ sowie durch Präpositionalgruppen ausgedrückt. Die originären Attribute des Substantivs hingegen werden durch vorangestellte flektierte Adjektive und nachgestellte Substantivgruppen im Genitiv oder Präpositionalkomplexe ausgedrückt. Daher ist die „substantivische Konstruktion“, wie Welke (2011: 254) schreibt, „Von einer verbalen Konstruktion [...] grundverschieden.“ Erst vor diesem Hintergrund wird die schul- und bildungssprachlich wichtige deverbale Nominalisierung als Form-Funktions-Verschiebung verständlich. ${ }^{65}$ Bei der Attribution von Substantiven zeigt sich, wie Fuhrhop und Thieroff (2005: 318) schreiben, die größte Variabilität, bei den Ergänzungen des Verbs die geringste.

Satzglieder und Attribute sind ähnlich gebaut. Aber ihre Einbettung ist verschieden. Beide bestehen auch wiederum aus Wortkomplexen oder Wortgruppen. Das Bauprinzip auf den verschiedenen Ebenen ist also ähnlich, was im Folgenden bezüglich der für die Schulsprache wichtigen Substantiv- und Adjektivgruppe skizziert wird.

63 Eine Besonderheit stellen diesbezüglich relationale Substantive wie Mutter (von jemandem) und Nominalisierungen von Verben wie Hoffnung (auf etwas) sowie von Adjektiven wie (der) Stolz (auf etwas/jemanden) dar.

64 Langacker (1991: 13) beschreibt diese konzeptuelle Unterscheidung mittels des Billardmodells. Diesem folgend lässt sich die Welt aus physisch diskreten Entitäten und energetischen Interaktionen zwischen diesen konzeptualisieren. Räumlich ausgedehnte Entitäten bilden den Prototyp des Nominalkonzeptes. Die zeitlich ausgedehnten Interaktionen und Prozesse bilden den Prototyp des Verbalkonzeptes.

65 Die Frage nach einem sekundären Wiedereinblenden einer verbalen Lesart deverbaler Nomen kann hier nicht besprochen werden. Ich verweise auf Welke (2016: 70-77). 
Handelt es sich um einen analytischen Substantivkomplex, so stehen die genuinen Adjektivattribute zwischen Artikel und Substantiv, also im Mittelfeld (das schöne Bild) und die genuinen Genitiv- (das Bild des Kindes) und Präpositionalattribute (das Bild von dem Kind) im Nachfeld. ${ }^{66}$

Nicht originär sind Attribute, die von einer höhren Ebene abgeleitet sind. Relativsatzattribute sind von der Satzebene (Textbaustein) abgeleitet. Von der Satzgliedebene abgeleitet sind umfunktionierte Adverbiale oder Situativergänzungen (das Bild dort/der Mann auf dem Sofa) sowie umfunktionierte Präpositionalobjekte (Hoffnung auf Frieden). Auf die gleiche Weise können entsprechende Nebensätze (Er hofft (darauf), dass Frieden herrscht) und Infintivkonstruktionen (Er hofft (darauf), in Frieden zu leben) zu Attributen umfunktioniert werden (die Hoffnung (darauf), dass Frieden herrscht/in Frieden zu leben). Die postnominale Stellung dieser nicht originären Attribute ist analog zur postverbalen Stellung in Aussagesätzen konstruiert. ${ }^{67}$ Daher schreibt Welke (2011: 261), „dass Präpositionalphrasen und insbesondere Adverbien primär in den Bereich der verbalen Konstruktion gehören.“ Ihre Umwertung, d.h. ihr Gebrauch auf einer anderen funktionalen Ebene, nämlich auf Wortgruppenebene bezeichnet Ágel (2017: 751) als „ein elementares funktionales Merkmal des grammatischen Systems“. Eine interessante, Einsicht vermittelnde Schulgrammatik muss jenes spannende Funktionsverhältnis, jene Umfunktionierung thematisieren.

Das flektierte (prototypische) Adjektivattribut besteht aus einem synthetischen Komplex (schön-e/-en). Nach Eichinger (1991: 312) „bringt [es] uns Eigenschaften des Bezugsnomens in Erinnerung, die in der Prädikation, in der die ganze Nominalgruppe steht, von Bedeutung sind, um die es aber nicht selber geht“. Bei mehreren Adjektivattributen entscheidet die Einbettung über die Zeichensetzung. Nur wenn sich die Bedeutungen der Adjektive gleichrangig (koordiniert) auf das Substantiv übertragen, wird ein Komma gesetzt (kluge, unterhaltsame Bücher). Hiervon zu unterscheiden ist der Fall, dass sich der dem Substantiv am nähesten stehende Adjektivkomplex attributiv zuerst auf das Substantiv bezieht. Ein zweiter Adjektivkomplex ist nun nicht mehr Attribut zum Substantiv, sondern zum bereits durch das erste Adjektivattribut erweiterte Substantiv ([spannende [französische Bücher]]). Das semantische Zentrum des Adjektivkomplexes kann

66 Nach Ronneberger-Sibold (2010: 89) gehört das Genitivattribut zwar zum Bezugssubstantiv, aber nicht zur Nominalklammer. Da innerhalb der Nominalklammer die Flexion der einzelnen Elemente zusammenspielt (der schöne Tag/ein schöner Tag), wird die Ausklammerung des Genitivattributs verständlich. Es würde die Klammerflexion nämlich durchbrechen. Einen Sonderfall in der Substantivgruppe stellen vorangestellte genitivische Eigennamen (Pauls Bild) und Possessivartikel-Pronomen (sein Bild) dar. Denn hier fallen Attribution und damit Gruppenbildung sowie Komplexbildung zusammen.

67 Cf. Eisenberg (2006: 58), Welke (2011: 260-261), Ágel (2017: 751-752). 
auch um Attribute erweitert werden, bevor es selbst das Substantiv attribuiert. So ist das Adverb sehr in (sehr schön-e) Attribut des Adjektivs. Ebenso können dem Adjektiv schrittweise temporale, kausale, modale oder lokale Attribute hinzugefügt werden (heute/hier wegen der milden Luft sehr schön-e). Einen Sonderfall stellen formal regierte (in der Adjektivvalenz angelegte) Adjektivattribute dar. Denn analog zu den verbalen Ergänzungen wird ihnen vom Adjektiv (vom semantischen Zentrum) ein Kasus (mir treu-e) oder eine Präposition (auf mich stolz-e) zugewiesen. Treten mehrere Attributtypen auf, so stehen die zeitlich, kausal, modal oder räumlich eingrenzenden Attribute vor den formal regierten und diese wiederum vor dem graduierenden Attribut (heute wegen der bestandenen Prüfung auf ihre Leistung sehr stolz-e). Vor den verschiedenen Attributen des Adjektivs kann jeweils auch ein kommentierendes Attribut treten (vermutlich heute sehr stolz-e/heute vermutlich wegen der bestandenen Prüfung sehr stolz-e). Verständlich wird das vor dem Hintergrund der Stellung beim prädikativen Gebrauch (Sie ist heute wegen der bestandenen Prüfung auf ihre Leistungen sehr stolz). Aus den primären Satzgliedern Temporaladverbial, Kausaladverbial und Präpositionalobjekt werden Attribute, ohne dass sie als solche formal ausgezeichnet werden. Die formale Kennzeichnung der Überführung geschieht einzig am semantischen Zentrum stolz durch die Flexionsendung (struktuelles Zentrum) des Adjektivkomplexes.

Die Unterscheidung zwischen Wortkomplexen und Wortgruppen sowie die Differenzierung zwischen analytischen und synthetischen Komplexen zeigt Gemeinsamkeiten auf, ohne die wichtigen Unterschiede $\mathrm{zu}$ verwischen. Komplexe bestehen typischerweise aus einem strukturellen und einem semantischen Zentrum. Die semantischen Zentren der Komplexe sind durch andere Komplexe und Gruppen schrittweise erweiterbar. ${ }^{68}$ Das semantische Zentrum des Verbkomlexes wird durch Satzglieder (Ergänzungen und Angaben) zum Ausdruck von Ereignissen erweitert. Die semantischen Zentren aller anderen Komplexe werden, falls dies möglich ist, durch Attribute erweitert. Diese können in der Valenz des jeweiligen semantischen Zentrums angelegt sein oder nicht. Sie können originär oder analog zur Ebene der Satzglieder umfunktioniert sein.

Die lange Zeit durch das Verzeichnis der Kultusministerkonferenz (1982) geforderte Theorieneutralität wurde in dem reformierten Verzeichnis der Kultusministerkonferenz (2019) aufgegeben. Will die Schulgrammatik - was sie muss dicht am heutigen Wissensstand sein, so kann sie nicht theorielos sein. Denn alles, was die Schulgrammatik beinhaltet, ist auch theoretisch. Konstituenz und

68 Teilweise kann die Reihenfolge der schrittweisen Komplexbildung je nach Verständnis (von engeren und weiteren Beziehungen) variieren. Denn die Reihenfolge der Anbindung muss formal nicht ausgezeichnet sein. Cf. Fuhrhop und Thieroff (2005: 328-330), Welke (2007: 82-83). 
Dependenz als wesentliche Strukturaspekte von Sprache sind theoretische Konstrukte, mittels derer Strukturen beschrieben werden. ${ }^{69}$

\section{Schulgrammatik zwischen Erst- und Zweit- sprachperspektive}

Die bereits angesprochene Ablehnung jeglicher Schulgrammatik durch Grimm (1819) hat einen wesentlichen Grund in der Annahme bzw. dem Mythos des perfekten Muttersprachlers. So schreibt Grimm (1819: XI) in Anlehnung an Charles Villers: „Jeder Deutsche, der sein Deutsch schlecht und recht weiß, d.h. ungelehrt, darf sich [...] eine selbsteigene, lebendige Grammatik nennen und kühnlich alle Sprachmeisterregeln fahren lassen."70 Die Idee und entsprechende Bilder wie der Vergleich des Spracherwerbs mit der Aufnahme der Muttermilch im Hause sind in deutschen Grammatiken nicht neu. Sie findet sich in Abgrenzung zu lateinischen Sprachlehren seit Ickelsamer (1535: I), der die Grammatik als „kinderwerck“ bezeichnet. Andererseits vermittelt dieses Bild indirekt, dass Grammatikunterricht nur dann zu rechtfertigen wäre, wenn es Defizite im sprachlichen Können gäbe, welche er beheben könnte. Dieser Irrtum wurde eingangs ausführlich besprochen. Ziel des expliziten Grammatikunterrichts ist der Aufbau von metasprachlichen Wissen, das Schaffen von Bewusstsein, welches mitunter helfen kann, den Erwerb des sprachlichen Könnens zu unterstützen.

Der romantische Mythos des perfekten Muttersprachlers wird schnell offensichtlich, wenn Grimm (1819: X) schreibt, vor sechshundert Jahren habe ,jeder gemeine Bauer Vollkommenheiten und Feinheiten der deutschen Sprache gewußt, d.h. täglich ausgeübt, von denen sich die besten heutigen Sprachlehrer nichts mehr träumen lassen. “ Wolfram von Eschenbach und Hartmann von Aue hätten die Biegung und Setzung von Substantiv und Verb reinlich beherrscht, ohne von „Declination noch von Konjugation je gehört“ zu haben. Grimm übernimmt den von Wolfram inszenierten Mythos des Analphabeten oder verwechselt den Erzähler von Parzival mit Wolfram. Heute könnten wir nur mehr auf gelehrte Weise jene grammatischen Formen entdecken, dürften die Sprache aber nicht

69 Letztlich ist die Frage nach Konstrukt und Fakt eine philosophische. Gehen wir a priori von einem System hinter dem Gebrauch aus - oder sehen wir das System als emergentes Phänomen des Gebrauchs? Letzteres wird innerhalb gebrauchsbasierter Modelle z. B. von Langacker (1991) angenommen.

70 Ein gutes Haar lässt Grimm (1819: XXI) an der Schulgrammatik, nämlich dass sie die lateinische Terminologie vermittele, welche gegenüber den zahlreichen Verdeutschungsversuchen die nötige Abstraktheit grammatischer Begriffe erlaube. 
in ältere (für Grimm jüngere) Entwicklungsstufen zurückführen, da sie „ihren unabänderlichen Gang“ gehe. So progressiv Letzteres ist, so unverständlich ist, was der gemeine Bauer mit mittelhochdeutschen Epen bezüglich der Grammatik gemein hat. Auf einem ganz anderen Blatt steht freilich, dass grammatische Instruktion weder zum Sprachkönnen des gemeinen Bauers noch zum Verfassen von Epen führt.

Die Idee des kompetenten Muttersprachlers findet sich auch später z.B. bei Heringer (1974: 10), wenn er schreibt, dass ein Schüler im Mathematikuntericht lerne, mathematisch zu handeln. Sprachlich handeln könne er jedoch schon, wenn der Deutschunterricht beginnt. Dies stimmt für Gebrauchsdomänen, in denen das Kind aufwächst und sprachlich handelt. Je nach Herkunft kann es auch auf die Bildungssprache zutreffen. Keinesfalls stimmt es in Bezug auf die Schulsprache.

Strukturen und deren Reflexion, um die es primär in der Schule geht, sind eben solche, denen Kinder in ihren Handlungsdomänen gewöhnlich nicht begegnen. Die Schulsprache ist nach Feilke (2012: 151, 153-155) ein didaktisches Register, welches in der Schule gebraucht und von der Schule als präskriptive Norm erschaffen werde. Ein wesentlicher Nutzen bestehe darin, dass es sich um Transitnormen handele, welche eine Art Steigbügel zur Bildungssprache darstellen. Grammatikunterricht hingegen hat den Erwerb metasprachlichen Wissens zum Ziel.

In dieser Hinsicht ist Adelung (1782: 17) zu verstehen, wenn er schreibt, dass die Standardsprache bewusst gelernt werden müsse und die Grammatik die Richtigkeit der Ausdrücke festlege. Die Diskrepanz zu Grimm verwundert nicht. Adelung (1782) schreibt seine Sprachlehre im Auftrag des preußischen Kultusministers von Zedlitz. ${ }^{71}$ So trägt sie auch den Zusatz Zum Gebrauch der Schulen in den Kgl. Preussischen Landen im Titel. Allerdings betont Adelung (1782: 5, 18-19), dass es ihm um das Verständnis der Regeln durch Einsicht in Analogie gehe und betont die Normativität des Faktischen, also des Sprachgebrauchs. Allerdings geht es um den Sprachgebrauch der besten Schriftsteller. Weicht dies auch stark von einem modernen korpuslinguistisch zu fundierenden Standardbegriff $\mathrm{ab},{ }^{72}$ so bleibt doch die Tatsache, dass die Standardsprache, insbesondere die Bildungssprache als Register medial und konzeptionell auch von Erstsprachlern sprechend, lesend und schreibend gelernt werden muss, und zwar umso mehr, je weniger ,Hauskontakt‘ Kinder mit jenem Register haben. Die Grammatik dient der Reflexion, dem Verständnis und der Einsicht, welche bestenfalls Steigbügel für sprachliches Können bilden.

71 Zur Rolle Adelungs Sprachlehre cf. Polenz (2002).

72 Cf. Kupietz und Keibel (2009). 
Darauf, dass die Standardsprache nicht einfach die verschriftete Form einer beherrschten Muttersprache ist, macht auch Eisenberg (2004: 15) aufmerksam. Granzow-Emden (2014: 8-9) vergleicht die Aneignung der Standardschriftsprache mit dem Erwerb der ersten Fremdsprache. Man mag dies - aufgrund vorhandener Anschlussstellen zur Mündlichkeit - für überspitzt halten. Fest steht aber, dass es sich bei der Schulsprache um ein neues Register handelt, welches in vielen Bereichen neu zu lernen ist. Im engeren Bereich grammatischen Könnens umfasst dies zu lernende Paradigmen wie beispielsweise die Formen des Konjunktiv Präsens und im Bereich der Syntax die verschiedenen Möglichkeiten zur Wiedergabe direkter Rede, Form und Gebrauch passivierender Strukturen, korrelative Konnektoren und verdichtende komplexe Attribution. Genauso ,neu` zu lernen sind grammatische Begriffe, Testverfahren und explizite Kenntnisse über Form-Funktionszusammenhänge. Aber auch hier gilt es, nicht in die Nutzenfalle zu tappen. Die Schulgrammatik als Grammatik für Lehrende muss jene Strukturen so gut wie möglich erklären. Das zu vermittelnde Wissen bildet einen wesentlichen Hintergrund, um in der Schule metasprachliche Kompetenzen zu entwickeln.

Berücksichtigen wir darüber hinaus die steigenden Zahlen von Schülern, deren erste Sprache (Haussprache) nicht deutsch ist, so kann noch viel weniger von einem Unterricht ausgegangen werden, der die „,beherrschte, vertraute“ Sprache zum Gegenstand hat. Als Beispiel mögen die Zahlen in Berlin aus dem Schuljahr 2019/20 stehen. Laut Senatsverwaltung für Jugend, Bildung und Familie ${ }^{73}$ machen Schüler nichtdeutscher Herkunfstsprache an öffentlichen Schulen 40,6\% der Gesamtschülerzahl aus, in Grundschulen 45\%, in integrierten Sekundarschulen 42,6\% und an Gymnasien 28\%. In dem Stadtbezirk Berlin Mitte zum Beispiel machen Schüler nichtdeutscher Herkunftssprache an öffentlichen Schulen $73,6 \%$ aus.

Was heißt das nun für die universitäre Schulgrammatik? Das heißt, sie muss künftige Lehrer dazu befähigen, auch eine Außenperspektive auf die deutsche Grammatik einnehmen zu können. ${ }^{74}$ Und das wiederum kann bedeuten, dass bestimmte Kategorien verstärkt behandelt werden müssen. Bei einer Umfrage unter 1019 Deutschlehrern und Referendaren ermitteln Topalovic und Dünschede (2014: 78-79), dass diese im Hinblick auf mehrsprachige Schüler andere Gewichtungen für sinnvoll halten. Während Artikel und Kasus bei der Frage nach den

73 https://www.berlin.de/sen/bildung/schule/bildungsstatistik/ (13.05.20).

74 Diese den Sprachvergleich einschließende Betrachtung wird spätestens seit Jolly (1874: 83) und bis heute u. a. von Helbig (1992b: 154) und Hoffmann (2011: 38) gefordert. Ossner (2008: 56) bezeichnet Mehrsprachigkeit nicht nur als Ausgangslage, sondern als Ziel des Deutschunterrichts. Zudem fordert das Bundesamt für Migration und Flüchtlinge (2010: 49), dass Lehrer aller Fächer in ihrem Studium verpflichtend in die Vermittlung von Deutsch als Zweitsprache eingeführt werden. 
„zehn wichtigsten grammatischen Termini im Unterricht“ eine geringe Rolle spielen und die Wortstellung gar nicht genannt wird, zählen diese im Hinblick auf Mehrsprachigkeit zu den wichtigsten Themen. In Bezug auf Gewichtungen ist ebenso mehr Wissen, mehr Forschung über systematischen Fehl-, Zuviel- und Zuwenig-Gebrauch (mis-, over-, underuse) bestimmter Strukturen durch DaZ/FSprecher nötig. ${ }^{75}$

Es sei auch hier wieder vor der Nutzenfalle gewarnt. Die Gewichtungswünsche der befragten Lehrer sollten primär als Wünsche für die eigene grammatische Ausbildung, nicht direkt für ihre Vermittlung in der Schule verstanden werden. Denn auch im Bereich DaZ/F ist es umstritten, inwiefern sich die explizite grammatische Instruktion der Schüler auf ihr sprachliches Können auswirkt. Bestenfalls kann metasprachliche Kompetenz das Sprachkönnen fördern, indem sie Erwerbsprozesse abkürzt und Input basiertes Lernen umgeht, wie Andringa und Rebuschat (2015: 189) schreiben.

Die Langzeitstudie zum DaF-Erwerb an Genfer Schulen von Diehl et al. (2000: 359) zeigt, dass sich der explizit vermittelte Grammatikstoff häufig nicht unmittelbar in der freien Textproduktion der Lernenden widerspiegelt. Vieles deutet darauf hin, dass der Erwerb grammatischen Könnens eher einem internen Lehrplan als dem expliziten Grammatikunterricht folgt. Das bekräftigt eine Forderung nach der sogenannten Teachability-Hypothese, ${ }^{76}$ dass der Grammatikunterricht den natürlichen Erwerbssequenzen folgen müsse. Diehl et al. (2000: 376) plädieren zudem für eine Anpassung der grammatischen Progression an die Verarbeitungskapazität der Lerner. Das heißt im Klartext eine Reduktion des Stoffes als „Einsicht in das realistisch Machbare“. Dies heißt keineswegs eine Abschaffung expliziten Grammatikunterrichts. So plädiert Handwerker (2009: 97-99) für einen „aufdringlichen“ Input für Lernende durch Lehrende, welcher Erwerbsmechanismen in Gang setzen soll. Hierbei geht es um präpariertes Unterrichtsmaterial, in welchem einzelne Strukturen als Form-Bedeutungspaare häufig vorkommen, die holistisch als Chunks entnommen und zu Konstruktionen abstrahiert werden können, wenn dies durch explizite grammatische Instruktion begleitet wird. ${ }^{77}$

75 So zeigen z. B. Hirschmann et al. (2013: 229), dass DaF-Lernende die Kategorie Adverb in der gleichen Textsorte signifikant seltener gebrauchen als L1-Sprecher. Dies gilt besonders für komplexe Adverbgruppen und besondere Funktionen wie die als Modalpartikel.

76 Diese sagt nach Pienemann (1989: 60) voraus: „instruction can only promote language acquisition if the interlanguage is close to the point when the structure to be taught is acquired in the natural setting.“

77 Lütke (2011: 228-229) wertet die Ergebnisse ihrer explizit-formbezogenen Intervention bei der Vermittlung lokaler Präpositionen an Kinder mit nichtdeutscher Herkunftssprache insgesamt positiv aus. Wenn es sich vorerst auch nur um Hypothesen handele, scheint der explizite Fokus auf Formen auf diskursiver, syntaktischer, morphologischer und semantischer Ebene zu bes- 
Sowohl dieser Ansatz als auch die Berücksichtigung natürlicher Erwerbssequenzen macht es nötig, dass zukünftige Lehrer deutlich mehr als grammatisches Wissen benötigen. Nach Ahrenholz (2009: 28-29, 33-34) gehören hierzu aus dem Bereich der Zweitspracherwerbsforschung u. a. Wissen über die schulischen und außerschulischen Faktoren des Spracherwerbs, Wissen über Erwerbssequenzen als Indikatoren bestimmter Lernervarietäten sowie Wissen über den u-förmigen Erwerbsverlauf, Wissen über die relative sprachliche Komplexität sowie Einsicht, dass jeder Unterricht immer auch Sprachunterricht ist.

Die DaF/Z-Perspektive bedeutet für die Schulgrammatik als Grammatik für Lehrende erst einmal mit Helbig (1992b: 155) ein Maximum expliziter Grammatikkenntnisse als Optimum. Dieses Wissen dient primär der Sicherheit der Lehrenden, auch wenn sie es auf diesem Weg nicht direkt weitergeben können. Jene Sicherheit durch metasprachliche prozedurale und kategoriale Kompetenz ist deshalb so wichtig, weil sie eine Grundlage für die Zuwendung zu grammatischen Themen ist. Adressat jener Zuwendung sind, wie in jedem Fach, die Lernenden, nicht die Grammatik. Sprachliche Bewusstheit der Lehrenden muss grundlegendes Wissen über den Erwerb und damit über verschiedene Schritte hin zu zielsprachlichen Normen einschließen. Das erfordert die Verzahnung zwischen einem Verständnis von Grammatik als emergentem System (im Spracherwerb, in der Sprachentwicklung sowie im Sprachgebrauch) und den konkreten Fragen ihrer Vermittlung im Unterricht.

Hier sollen weder die verschiedenen Voraussetzungen noch Ergebnisse des Unterrichts von Erstsprachlern und Zweitsprachlern nivelliert werden. Praktisch müssen Lehrende an Schulen auf beide Gruppen von Lernern vorbereitet sein. Vielleicht ist eine Art der Vorbereitung, die Gemeinsamkeiten hervorzuheben, anstatt die Unterschiede zu betonen. Denn viele Unterschiede hängen stark von nicht-linguistischen Faktoren ab. Grammatikunterricht hat bei Erst- und Zweitsprachlern das Ziel, auf sprachliche Strukturen aufmerksam zu machen, Muster zu aktivieren, zu gebrauchen und Merkmale dieser Muster kennenzulernen. Eine wesentliche Voraussetzung dafür ist, dass zukünftige Lehrer Grammatik als einen spannenden Gegenstand des Nachdenkens verstehen.

Was die Linguistik als ein Zahnrad auch leisten kann und muss, ist die Relativierung jenes traditionellen Bildes der Grammatik als Peitsche, worum es in dem folgenden und letzten Abschnitt unter dem Stichwort ,falsch oder richtig‘ geht.

seren Ergebnissen zu führen. Dimroth (2009: 75-76) schlägt als Steigbügel für den Erwerb der Finitheitsposition aufdringlichen Input vor, der auf Vollverben in der linken Satzklammer verzichtet, um die Unterscheidung zwischen Verb und Finitheit zu erleichtern. 


\section{Schulgrammatik zwischen falsch und richtig?}

Lehrer müssen die Leistungen ihrer Schüler korrigieren und bewerten. Diese Aufgabe bringt die Natur der präskriptiven Schulsprache und der Institution Schule mit sich und hat mit Grammatik erst einmal weniger zu tun. Der Pädagoge Paul Georg Münch schreibt im Jahr 1909: „Wir wollten Pädagogen, Knabenführer sein und sind Buchführer geworden, Orthographenspäher, Zeichensetzer [...] Komma-Ausklügler, Zensurenschreiber." ${ }^{78}$ Das Problem ist didaktisch-pädagogischer und linguistischer Natur: Was ist überhaupt ein Grammatikfehler? Wie soll er korrigiert und bewertet werden?

Es ist seit langem bekannt, dass die Bewertungen von Aufsätzen von Lehrer zu Lehrer stark variieren. Eine Übersicht bieten Sitta und Tymister (1978: 72-78) sowie eine aktuellere Studie von Häcker (2009: 319-324). Die Heterogenität bei der Korrektur von Deutschaufsätzen findet sich auch im Teilbereich Grammatik. Hennig (2012: 138-140) lässt einen fiktiven Schülertext (6. Klasse, Nacherzählung) mit 23 präparierten (und zwei bei der Abschrift hinzugekommenen) potentiellen Grammatikfehlern von 15 Lehrern, zwei Referendaren und 23 Germanistikstudenten korrigieren. Die Probanden streichen insgesamt 57 verschiedene Grammatikfehler an. Demzufolge wurden 32 Fehler hineinkorrigiert. Dies spricht für die Aktualität des eingangs aufgeführten Zitats von Münch. Grammatikfehler werden auch dort korrigiert, wo es sich eher um stilistische, textsortenspezifische sowie konzeptionell-mediale Grade von Akzeptabilität unterschiedlicher Varianten handelt. Die Schulgrammatik muss also so gut wie möglich die Faktoren formulieren, auf welchen die Akzeptabilitätsurteile beruhen. Dies führt letztlich den Sprachgebrauch in Texten ins Feld. So zeigt Hennig (2012: 138) auch, dass die Probanden das mit der Aufgabenstellung „erzähle deinem Freund“ verbundene angemessene mündlichkeitsnahe Erzählen häufig als Fehler markiert haben.

Ein anderes interessantes Ergebnis der Studie von Hennig (2012) ist, dass kein Fehler von allen Korrektoren angestrichen wurde. Je nach Korrektor variierte individuell die Zahl der angestrichenen Fehler zwischen 5 und 30. Einerseits herrscht offensichtlich Unsicherheit bezüglich standardsprachlicher Korrektheit. Andererseits, sicher auch teilweise deshalb, wird zu streng korrigiert. Die Schulgrammatik muss standardsprachliche Korrektheit zu einem Eckpfeiler der Sprachbetrachtung machen. Viele präskriptive und damit der Fachwissenschaft

78 Münch, Paul Georg (1909): Rund ums rote Tintenfass. Essays über den Schüleraufsatz. Leipzig: Alfred Hahn. Zitiert aus Keller (1980: 23). 
erst einnmal ferne Sprachbeschreibungen decken sich mit der Deskription von Sprachstrukturen. Denn Normen liegen größenteils im System. ${ }^{79}$

Das Korrekturproblem findet sich genauso im Bereich DaF. Lüdeling (2008: 119) zeigt in einer kleinen Studie, dass fünf erfahrene DaF-Lehrer in einem Lernertext minimal drei und maximal zehn Artikelfehler als solchen kategorisiert bzw. korrigiert haben. Der Grund des Problems wird deutlich, wenn die Probanden gebeten werden, zu den lernersprachlichen Sätzen des Textes, die zielsprachliche Rekonstruktion (Zielhypothese) zu formulieren. Keiner der 17 lernersprachlichen Sätze wurde von allen fünf Korrekoren mit der gleichen Zielhypothese versehen (Lüdeling, 2008: 132). Zielhypothesen sind jedoch eine Bedingung dafür, einen Fehler zu klassifizieren. Denn erst vor dem Hintergrund entsprechender Ziehlhypothese kann von Abweichungen (eben von der Zielhypothese) bzw. von einem Fehler gesprochen werden. Umgekehrt gilt mit Cherubim (1980: 1), dass entsprechende Abweichungen von der Zielhypothese überhaupt erst die wie auch immer formulierte Regel, Norm oder Konstruktion hinter der Zielhypothese bestätigen.

Offensichtlich muss eine gute Schulgrammatik zwei Dinge leisten. Erstens muss sie für das Themenfeld Normen und Abweichungen sensibilisieren. Hierzu gehören linguistisch fundierte Fehlerbegriffe, welche von der Didaktik aufgenommen und in Bezug auf das Register Schulsprache nachvollziehbar angewendet werden können. Zweitens muss sie grammatische Variation (auch im Standard) zum Thema machen. Es sei an die verschiedenen Zielhypothesen zu einer von der Standardsprache abweichenden Struktur erinnert.

Zum grundlegenden Verständnis von Normen und Abweichungen gehört einerseits, dass Abweichungen ein ganz normaler, ja für Normen konstitutiver Bestandteil sprachlicher Praxis sind. Denn eine als Abweichung wahrgenommene, thematisierte und korrigierte Struktur stärkt die Norm, gegen welche verstoßen wurde ( ${ }^{\star}$ er gehte $\rightarrow$ er ging). Andererseits können Abweichungen am anderen Ende eines skalaren Fehlerbegriffs - zur Norm werden und ältere Normen verdrängen ( ${ }^{\star}$ er boll $\rightarrow$ er bellte). Die Schulgrammatik muss entsprechende Sprachwandelphänomene (z.B. durch Analogie, Frequenz, Größe von Proportionsgleichungen (quellen:quoll = bellen:boll versus stellen:stellte $=$ bellen:bellte)) verständlich machen. Denn Verständnis weckt Interesse. Eine solche Betrachtung führt dann auch zu einem differenzierten Fehlerbegriff, wie ihn zum Beispiel Ágel (2008: 66-67) in Bezug auf Coserius Unterscheidung zwischen System, Norm und Gebrauch vorschlägt. In Anlehnung daran können im Rahmen der Schulgrammatik unterschiedlich schwerwiegende grammatische Fehlertypen unterschieden werden. Hierbei muss von einem zweifachen Normenbegriff aus-

$79 \mathrm{Zu}$ Berührungspunkten zwischen explanatorischen und normativen Grammatiken cf. Kupietz und Keibel (2009: 34). 
gegangen werden. Die Ist-Norm betrifft häufige Realisierungen in den Daten, aus welchen Standards des geschriebenen Deutsch rekonstruiert werden, z. B. aus dem Archiv der geschriebenen Sprache des bereits erwähnten Deutschen Referenzkorpus (DeReKo). Hierbei handelt es sich um die Normativität des Faktischen. Und die Soll-Norm als sozial-präskriptive Norm, wie sie u.a. von der Institution Schule vermittelt, teils von ihr geschaffen wird und die sich z. B. in Ratgebern wie Richtiges und gutes Deutsch. Das Wörterbuch der sprachlichen Zweifelsfälle (2011) aber auch in der Sprachgebrauchskritik wiederfindet. Diese Vielschichtigkeit wird im Folgenden aufgezeigt. Ich beginne jeweils mit einem Beispiel.

(8) Für diesen Frauen, Feminismus existiert nicht, weil [... $]^{80}$

Der erste Systemfehler betrifft die Kasusmarkierung am Artikel. Unklar ist, ob der Lerner nicht weiß, dass die Form für den Akkusativ Plural diese ist oder dass die Präposition den Akkusativ regiert. Der zweite Fehler betrifft die Vorfeldbesetzung. In der Standardschriftlichkeit wird das Vorfeld im Aussagesatz von einem Satzglied oder dem infiniten Prädikatsteil mit eventuell weiteren Satzgliedern besetzt. Es handelt sich um Verstöße gegen die Ist- und gegen die Soll-Norm. Die Äußerung stammt von einer DaF-Lernerin.

(9) Warum rennen Menschen auf einer Tartanbahn, eine Runde nach der anderen? Weiß ich auch nicht so genau. ${ }^{81}$

Wie im vorhergehenden Fall handelt es sich auf den ersten Blick um eine formale Systemabweichung, hier durch Nicht-Besetzung des Vorfelds im Aussagesatz. In der (auch fingierten) Mündlichkeit handelt es sich um eine Ausdrucksroutine, eine Vorfeldellipse. Zifonun et al. (1997: 413, 418) schreiben von „situativen Ellipsen“, die „eine gemeinsame Vor-Orientierung von Sprecher und Hörer auf ein Element in der Sprechsituation (bzw. im mit der Sprechsituation gegebenen Wahrnehmungsfeld) als Argument des maximalen Prädikats“ übernehmen. Das regulär und somit systemkonform unbesetzte Vorfeld verweist direkt auf das Topik in der Sprechsituation (daher auch Topic-Drop). Es handelt sich um eine markierte Struktur.

80 Beleg $n z 002_{2} 007_{0} 5_{L} 2 v 2.0$ aus dem Falko-Korpus (Ein fehlerannotiertes Lernerkorpus des Deutschen als Fremdsprache) frei online durchsuchbar unter https://korpling.german.hu-berlin.de/ falko-suche/.

81 David Wagner, Spricht das Kind, Graz, 2009. 
(10) Ich liebe Dir! schwörte Kurt Schwitters einst der dadaistischen Muse Anna Blume. ${ }^{82}$

Es handelt sich um einen Systemfehler, da lieben seiner zweiten Ergänzung den Akkusativ zuweist (Rektion). In der Ist-Norm wird der Dativ nur als Zitat gebraucht. In der Soll-Norm wird er nicht akzeptiert. Dialektal ist es hingegen korrekt und könnte durch Hyperkorrektur bei niederdeutschem Zusammenfall von Akkusativ- und Dativpronomen ( mich/mir $\rightarrow$ mi, dich/dir $\rightarrow$ di) motiviert sein. ${ }^{83}$ Aus dialektaler Sicht handelt es sich bei ich statt $i k$ um eine Abweichung.

(11) Aber meines Erachtens nach erklärt das nicht den gesamten Sachverhalt. ${ }^{84}$

Es handelt sich um einen Systemfehler. Im DeReKo finden sich 1.885 Belege für einen Possessivartikel gefolgt von Erachtens nach gegenüber 26 Belegen mit Erachten nach. In der Soll-Norm wird die Abweichung jedoch nicht akzeptiert. Die Abweichung ist durch Analogie zu meines Erachtens und meiner Meinung nach bei Synkretismus der Genitiv- und Dativform bei Feminina motiviert. Sie wird deshalb nicht, richtiger‘, aber verständlich.

(12) Wer in der heißesten Phase der Saison nur zwei seiner jüngsten zehn Spiele gewinnt, braucht sich nicht wundern, wenn er ab März nicht um die Meisterschaft spielen darf. ${ }^{85}$

Die Verwendung von nicht brauchen ohne $z u$ ist systemkonform bei konfligierenden Teilsystemen (Modal- vs. Halbmodalverben). In der Ist-Norm finden sich Belege ohne $z u$ deutlich seltener als mit. Von der Soll-Norm wird der Übergang zum Muster der Modalverben nicht akzeptiert. Die semantische Analogie zu nicht müssen erklärt die formale Angleichung bis zum Wegfall des Verbalflexivs er brauch in der gesprochenen Sprache.

(13) Diebe haben in Dörsdorf ein lilanes BMX-Rad [...] gestohlen. ${ }^{86}$

82 Die Zeit, 20.08.1993, S. 41.

83 So heißt es auf niederdeutsch „Dreih di üm, dat ik di ankieken kann!“ http://www.plattart. de/2010/programm_26-09-2010.htm (16.06.18).

84 die tageszeitung, 15.12.2005, S. 27.

85 Westdeutsche Zeitung, 29.01.2018.

86 Rhein-Zeitung, 08.10.2012, S. 12. 
Es handelt sich um die systemkonforme Flexion (Nominalflexion) eines Adjektivs maskulin, Singular, Akkusativ mit unbestimmtem Artikel. Allerdings ist das auf einen Vollvokal auslautende lila genauso wie manche von Substantiven abgeleitete Adjektive ein atypisches Adjektiv und gilt als nicht flektierbar. In der IstNorm finden sich flektierte Formen viel seltener (82 flektierte Formen von lila im DeReKo) als unflektierte (allein mit definitem und indefinitem Artikel 3000 Belege). In der Soll-Norm wird die flektierte Form als umgangssprachlich abgelehnt.

(14) In bester Karnevalsmanier wurde geklatscht, gewunken, aufgestanden und sich wieder gesetzt. ${ }^{87}$

Die Abweichung (gewunken statt gewinkt) ist systemkonform bei konfligierenden Teilsystemen. In der Ist-Norm finden sich 1.305 unflektierte Belege für gewunken, welches von der Soll-Norm als umgangssprachlich stigmatisiert wird. Das von der Soll-Norm geforderte (weil ältere?) gewinkt findet sich im DeReKo mit 809 Belegen. Die starke Form gewunken lässt sich durch analoge Proportionsgleichungen im System schwingen:geschwungen = winken:gewunken und durch Hyperkorrektur erklären.

(15) Eines Nachts schaffte es Aschwak zu fliehen. ${ }^{88}$

Bei eines Nachts handelt es sich um eine Systemabweichung, die in der Ist-Norm als einzig gebrauchte Form etabliert ist. Auch in der Soll-Norm ist es die einzig akzeptierte Form. Die Bildung basiert auf Analogie zu eines Tages, obwohl bei Feminina der Genitiv ausschließlich am Artikel einer Nacht markiert wird.

Die Differenzierung und Erklärung von Abweichungen bieten Einsicht und Verständnis für sprachliche Teilsysteme, verschiedene Normebenen und Sprachgebrauchsformen. In diesem Sinne muss die Schulgrammatik auch ein Instrument zur Fehlerdifferenzierung sein.

Grammatikunterricht, an welchen die Schulgrammatik anschlussfähig sein muss, steht unter Zwängen (Soll-Norm), unter denen die wissenschaftliche Grammatik nicht steht. Dies sollte die Schulgrammatik jedoch nicht daran hindern, Normdifferenzen zu thematisieren und gegebenenfalls, wie Heringer (1978: 26) schreibt, als „das Shibboleth der geistigen happy few“ zu hinterfragen. Grundsätzlich stellt Takada (1998: 15) bezüglich beider Normebenen die folgende, auch

87 Mannheimer Morgen, 18.07.1995.

88 Merkur, 20.08.2018. 
für die Schulgrammatik wichtige Frage: „Laufen die grammatischen Kodifizierungen parallel mit dem herrschenden Sprachgebrauch oder laufen sie ihm hinterher oder voraus?“ Dieses Spannungsfeld kann und muss zu einem spannenden Unterrichtsgegenstand werden. Voraussetzung hierfür ist, dass die Lehrer entsprechend ausgebildet sind. Auch hier gilt das bereits thematisierte Maximum an grammatischem Wissen. Diesbezüglich schreibt Eisenberg (2004: 23): „Sprache, Sprache und nochmal Sprache in die Lehrerbildung. Und grundlegend dabei bleibt das grammtische Wissen der Lehrer.“

$\mathrm{Zu}$ jenem Mehr an Grammatik gehört auch das eingangs angesprochene Sprachspiel. Grammatik erlaubt jenes Spiel und macht es überhaupt erst möglich. Es geht um eine Facette, „von endlichen Mitteln einen unendlichen Gebrauch [zu] machen“ (Humboldt 1836: 106, § 13). Um jenes Spiel richtig zu spielen und zu verstehen, bedarf es u. a. vor dem Hintergrund grammatischer Variation auch des Konstruktionsbegriffes. Im zweiten Abschnitt wurde die traditionelle Satzanalyse valenziell untermauert. Nun gibt es aber gerade im Bereich der Verbvalenz ganz erhebliche Variation. Es handelt sich um Erhöhungen und Reduktionen in Bezug auf die Grundvalenz. Die Abweichungen können kategorial (routiniert) sein, z. B. beim Passiv (Valenzreduktion). Sie können aber auch mehr oder weniger ad hoc und kreativ sein. ${ }^{89}$ Betrachten wir hierzu den Satz in (16).

(16) Kate Perry [...] hat bei einem Konzert in Moskau die Halle leer gesungen. ${ }^{90}$

Die Satzglieder lassen sich zwar im traditionellen Sinne als Subjekt, Akkusativobjekt und resultatives Objektsprädikativum beschreiben. Aber jene Beschreibung erklärt weder die Abweichung von der Grundvalenz ( ${ }^{\star}$ sie hat die Halle gesungen) noch die damit einhergehende Veränderung der Grundbedeutung (sie verursacht durch ihr Singen, dass die Halle leer wird). Die im dritten Abschnitt skizzierte valenzielle Satzanalyse stößt an ihre Grenzen. Aufgrund jener Veränderung des erwartbaren Szenarios (Sie hat ein Lied gesungen) schreibt Ágel (2017: 47-50) von „Umszenierungen“, was eingedenk der Drama-Metapher von Tesnière (1959: 102, $\S 1)$ sehr bildlich ist. Das Phänomen lässt sich gut erfassen, wenn die gesamte Struktur aus Subjekt, finitem Verb, Objekt und resultativem Objektsprädikativum als Resultativkonstruktion betrachtet wird. Der formalen Struktur entspricht funktional, dass der Subjekt-Referent durch sein verbales Tun verursacht, dass der Referent des Akkusativobjektes in den vom Prädikativum bezeichneten $\mathrm{Zu}$ -

89 Stein (1995: 108-109) schlägt die Begriffe Routine als reproduktives Aufgabenbewältigen und Kreativität als Neues schaffendes Problemlösen vor. Ágel (2017: 50) wendet das Konzept auf statische und dynamische Valenzen an.

90 Hamburger Abendblatt, 09.06.09. 
stand gerät. Diese syntaktisch-semantische Schablone lädt durch Neubesetzung der Konstruktionsstellen zum sprachlichen Spiel und zur Ermittlung seiner Grenzen ein. Ebenso wird klar, dass Konstruktionen selbst ebenso zu sprachlichen Routinen gehören. Kreativ sind ihr Gebrauch und Verständnis durch nicht mit ihnen assoziierten Verben. Routine und Kreativität gehen Hand in Hand.

Das Phänomen der Resultativkonstruktion wird in der Sprachwissenschaft kontrovers diskutiert. ${ }^{91}$ Diese Kontroversen kann die Schulgrammatik natürlich nicht lösen. Aber es wird offensichtlich, dass neben der Valenztheorie als einer Säule der Satzgliedanalyse auch ein Beschreibungs- und Operationsbegriff nötig ist, der u.a. jene Valenzvarianten erfasst. Hierzu bietet sich das Konzept der Argument-Konstruktion als Einheit aus Form und Bedeutung aus der Konstruktionsgrammatik an. Denn die Beschäftigung mit Zusammenhängen zwischen konkreter Form und Funktion ist ein Grundanliegen der Schulgrammatik. Das klassische Valenzkonzept erfordert den Blick vom Verb in den Satz. Der Konstruktionsbegriff erfasst syntaktische Konfigurationen holistisch und setzt bei ihnen die Analyse an. Dies ist für alle die Fälle von Bedeutung, in denen produktive Muster in kreativer und routinierter Abweichung zur Grundvalenz analysiert und gebildet werden.

\section{Fazit}

Die Schulgrammatik ist weder ein Hassobjekt noch Objekt der Liebe. Und das soll sie auch nicht sein. Befreit von dem akademischen Negativdiskurs über sie und überspitzten Erwartungen an sie, soll sie Lehrern ein umfassendes Wissen und Verständnis grammatischer Strukturen, ihrer Bildung und Ermittlung erlauben. Gleichsam stellt sie eine wesentliche Voraussetzung für fachdidaktisches Wissen und natürlich für den schulischen Grammatikunterricht dar.

Den Spagat zwischen verschiedenen Theorien, zwischen Deutsch als Erstund Zweitsprache sowie zwischen sprachlichen Systemen, Ist- und Soll-Normen kann sie nur bestehen, indem sie sprachwissenschaftliche Erkenntnisse aus verschiedenen theoretischen Richtungen aufnimmt, ohne selbst eine vollständige Theorie zu sein und ohne in den Widerstreit theoretischer Debatten zu geraten. Das wahre Problem der Schulgrammatik besteht in falsch verstandener Therieneutralität als Theorieabstinenz. Ein anderer Spagat ist der zwischen Schulgrammatik und ihrer Anwendung in der Schule. Sicher stehen Wissen als Gut und auch Lernen als Anstrengung zur Zeit nicht hoch im Kurs. Aber so wie die Fachdidaktik

91 Cf. Felfe (2012: 354-359). 
fachwissenschaftliche Kenntnisse voraussetzt, so setzt sprachliches Bewusstsein profunde Kenntnisse voraus. Wissen über einen Gegenstand zu erwerben, steht der Freude an ihm ebenso wenig gegenüber wie grammatische Regeln der sprachlichen Kreativität. Entscheidend ist, dass entsprechende Regelmäßigkeiten gut formuliert sind und möglichst zu mehr Verständnis führen. Damit dies geschehen kann, muss sich die Schulgrammatik mit Grammatik beschäftigen, ohne voreilig auf eine direkte Anwendbarkeit oder einen messbaren Nutzen abzuzielen.

Der Beitrag der Fachwissenschaft zur Schulgrammatik kann nicht den Umgang mit grammatischen Abweichungen regeln. Aber er kann die herrschende Falsch-Richtig-Dichotomie dort aufweichen, wo sie den Blick auf Sprache und Sprachentwicklung verstellt. Die Schulgrammatik muss für sprachliche Variation sensibilisieren, den Mythos sprachlicher Homogenität aufdecken, damit die Grammatik in der Schule keine puristische, primär mit dem Rotstift assoziierte Verfechterin einzelner Varianten ist. Auf ihrer Grundlage müssen grammatische Normen vermittelt und bestmöglich begründet werden, so dass auch die Abweichungen davon erklärt werden können. Ein Verständnis für sprachliche Variation ist Voraussetzung für den angemessenen Umgang mit Varianten und die Korrektur von Fehlern. Der konstruktive Beitrag der Schulgrammatik muss sein, den Prototyp so exakt wie möglich zu beschreiben, Abweichungen so weit wie möglich in Bezug auf andere Prototypen zu erklären und somit Verständnis für das sich bedingende Wechselspiel zwischen Regel, Norm und Abweichung zu schaffen. Gelingen kann dies nur, wenn sie auch die der Sprachwissenschaft erst einmal ferne sozial-präskriptive Norm ernst nimmt und in jenem Wechselspiel zum Thema macht.

Danksagung: Für Kommentare und Anregungen danke ich Torsten Föste, Eva Schlachter, Stefan Müller, Beate Lütke und den anonymen Gutachtern.

\section{Literatur}

Adelung, Johann Christoph (1782). Deutsche Sprachlehre. Zum Gebrauch der Schulen in den Kgl. Preussischen Landen. Wien: J. Th. Edlen von Trattern.

Ágel, Vilmos (1996). Finites Substantiv. Zeitschrift für Germanistische Linguistik 24(1), 16-57. Ágel, Vilmos (2000). Valenztheorie. narr studienbücher. Tübingen: Narr.

Ágel, Vilmos (2008). Bastian Sick und die Grammatik. Ein ungleiches Duell. Info DaF 35(1), 64-84.

Ágel, Vilmos (2017). Grammatische Textanalyse. Textglieder, Satzglieder, Wortgruppenglieder. Berlin, Boston: De Gruyter.

Ahrenholz, Bernt (2009). Vom Nutzen der Zweitspracherwerbsforschung für die Ausbildung von Lehrerinnen und Lehrern. Zeitschrift für Literaturwissenschaft und Linguistik 39(1), 26-38. 
Andresen, Helga (1985). Schriftspracherwerb und die Entstehung von Sprachbewusstheit. Opladen: Westdeutscher Verlag.

Andringa, Sible und Patrick Rebuschat (2015). New directions in the study of implicit and explicit learning. An introduction. Studies in Second Language Acquisition 37(2), 185-196.

Becker, Karl-Ferdinand (1837). Ausführliche deutsche Grammatik als Kommentar zur Schulgrammatik. Statt einer zweiten Auflage der deutschen Grammatik, Bd. 2. Frankfurt am Main: G. F. Kettembeil.

Becker, Karl-Ferdinand (1845). Schulgrammatik der deutschen Sprache (5. Aufl.). Frankfurt am Main: Kettembeil.

Boettcher, Wolfgang (1994). Grammatiksozialisation in Schule, Hochschule und Referendarausbildung. Beiträge zur Lehrerinnen- und Lehrerausbildung 12(2), 170-186.

Boettcher, Wolfgang und Horst Sitta (1978). Der andere Grammatikunterricht. Veränderungen des klassischen Grammatikunterrichts. Neue Modelle und Lernmethoden. München, Wien, Baltimore: Urban und Schwarzenberg.

Braun, Christian (2013). Zur Konzeptualisierung des Grammatikbegriffs. In Klaus-Michael Köpcke und Arne Ziegler (Hg.), Schulgrammatik und Sprachunterricht im Wandel, Reihe Germanisitsche Linguistik, S. 17-34. Berlin, Boston: De Gruyter.

Bredel, Ursula (2005). Sprachstandsmessung - eine verlassene Landschaft. In Bundesministerium für Bildung und Forschung (Hg.), Anforderungen an Verfahren der regelmäßigen Sprachstandsfeststellung als Grundlage für die frühe und individuelle Förderung von Kindern mit und ohne Migrationshintergrund, Bildungsreform, S. 78-120. Bonn, Berlin: BMBF. URL https://d-nb.info/978298160/34.

Bredel, Ursula (2013). Sprachbetrachtung und Grammatikunterricht (2., durchges. Aufl.). StandardWissen Lehramt - Studienbücher für die Praxis. Paderborn: Schöningh.

Bremerich-Vos, Albert (1999). ,Farbiger‘ Grammatikunterricht. Studierende und ihre ,Grammatikbiografien؛ In Peter Klotz und Ann Peyer (Hg.), Wege und Irrwege sprachlichgrammatischer Sozialisation. Bestandsaufnahme - Reflexionen - Impulse, S. 25-52. Hohengehren: Schneider.

Bundesamt für Migration und Flüchtlinge (2010). Bundesweites Integrationsprogramm. Angebote der Integrationsförderung in Deutschland - Empfehlungen zu ihrer Weiterentwicklung. URL http://www.bamf.de/SharedDocs/Anlagen/DE/Downloads/Infothek/ Integrationsprogramm/bundesweitesintegrationsprogramm.pdf?_blob=publicationFile.

Cherubim, Dieter (1980). Fehlerlinguistik. Sprachliche abweichungen als gegenstand einer germanistischen linguistik. Zeitschrift für germanistische Linguistik 8(1), 1-22.

Diehl, Erika, Helen Christen, Sandra Leuenberger, Isabelle Pelvat und Thérèse Studer (2000). Grammatikunterricht: Alles für die Katz? Untersuchungen zum Zweitspracherwerb Deutsch. Reihe Germanistische Linguistik. Tübingen: Niemeyer.

Dimroth, Christine (2009). Lernervarietäten im Sprachunterricht. Zeitschrift für Literaturwissenschaft und Linguistik 39(1), 60-79.

Dowty, David R. (1991). Thematic Proto-Roles and Argument Selection. Language 67(3), 547-619.

Duden-Grammatik (2016). Der Duden in zwölf Bänden. Grammatik (9. vollständig überarbeitetete und aktualisierte Aufl.). Berlin: Dudenverlag. Herausgegeben von Angelika Wöllenstein und der Dudenredaktion.

Dürscheid, Christa (2007). Damit das grammatische Abendland nicht untergeht. Grammatikunterricht auf der Sekundarstufe II. In Klaus-Michael Köpcke und Arne Ziegler (Hg.), 
Grammatik in der Universität und für die Schule, Reihe Germanistusche Linguistik. Tübingen: Niemeyer.

Dürscheid, Christa (2010). Lateinische Schulgrammatik oder andere Modelle? Welche Grammatik eignet sich am besten zur Beschreibung des Deutschen? In Mechthild Habermann (Hg.), Grammatik wozu? Vom Nutzen des Grammatikwissens in Alltag und Schule, Thema Deutsch. Mannheim, Zürich: Dudenverlag.

Eichinger, Ludwig M. (1991). Ganz natürlich - aber im Rahmen bleiben. Zur Reihenfolge gestufter Adjektivattribute. Deutsche Sprache 19(4), 312-329.

Eisenberg, Peter (1976). Wissenschaftliche Grammatik in der Sprachlehre. DAS ARGUMENT 1976(95), 9-23.

Eisenberg, Peter (2004). Wieviel Grammatik braucht die Schule. Didaktik Deutsch 17(2004), 4-25.

Eisenberg, Peter (2006). Grundriss der deutschen Grammatik. (3., durchges. Aufl.), Bd. 2: Der Satz. Stuttgart, Weimar: Metzler.

Eisenberg, Peter (2013). Schulgrammatik - Sprache für Schüler, Sprachwissen für Lehrer. In Klaus-Michael Köpcke und Arne Ziegler (Hg.), Schulgrammatik und Sprachunterricht im Wandel, Reihe Germanistische Linguistik, S. 7-13. Berlin, Boston: De Gruyter.

Erben, Johannes (1955). Prinzipielles zur Syntaxforschung, mit besonderem Blick auf Grundfragen der deutschen Syntax. Beiträge zur Geschichte der deutschen Sprache und Literatur (PBB) 76(1), 144-165.

Feilke, Helmuth (2012). Schulsprache - Wie Schule Sprache macht. In Susanne Günther, Wolfgang Imo, Dorothee Meer, und Jan Georg Schneider (Hg.), Kommunikation und Öffentlichkeit. Sprachwissenschaftliche Potentiale zwischen Empirie und Norm, S. 149-175. Berlin, Boston: De Gruyter.

Feilke, Helmuth (2013). Bildungssprache und Schulsprache - am Beispiel literal-argumentativer Kompetenzen. In Michael Becker-Mrotzek, Karen Schramm, Eike Thürmann, und Helmut Johannes Vollmer (Hg.), Sprache im Fach. Sprachlichkeit und fachliches Lernen, Fachdidaktische Forschungen, S. 113-130. Münster: Waxmann.

Feilke, Helmut und Doris Tophinke (2016). Grammatisches Lernen. Basisartikel. Praxis Deutsch 256, 4-13.

Felfe, Marc (2012). Transitive Resultativkonstruktionen in der Konstruktionsgrammatik. Zeitschrift für Germanistische Linguistik 40(3), 352-395.

Fuhrhop, Nanna und Rolf Thieroff (2005). Was ist ein Attribut? Zeitschrift für Germanistische Linguistik 33(2-3), 306-342.

Funke, Reinold (2005). Sprachliches im Blickfeld des Wissens. Grammatische Kenntnisse von Schülerinnen und Schülern. Tübingen: Niemeyer.

Gaiser, Konrad (1950). Wieviel Grammatik braucht der Mensch? In Hans G. (1973) Rötzer (Hg.), Zur Didaktik der deutschen Grammatik, S. 1-15. Darmstadt: Wissenschaftliche Buchgesellschaft.

Glinz, Hans (1952). Die innere Form des Deutschen. Eine neue deutsche Grammatik. Bern, München: Francke.

Granzow-Emden, Matthias (2014). Deutsche Grammatik verstehen und unterrichten (2., überarb. Aufl.). bachelor wissen. Tübingen: Narr Francke Attempto Verlag.

Grimm, Jacob (1819). Deutsche Grammatik. Erster Theil. Göttingen: Dieterichsche Buchhandlung.

Gärtig, Anne-Kathrin, Albrecht Plewnia und Astrid Rothe (2010). Wie Menschen in Deutschland über Sprache denken. Ergebnisse einer bundesweiten Repräsentativerhebung zu aktuellen 
Spracheinstellungen. Arbeitspapiere und Materialien zur Deutschen Sprache. Mannheim: Institut für Deutsche Sprache.

Günther, Hartmut und Ellen Nünke (2005). Warum das Kleine groß geschrieben wird, wie man das lernt und wie man das lehrt. Kölner Beiträge zur Sprachdidaktik 1/2005, 2-57.

Habermann, Mechthild, Gabriele Diewald und Maria Thurmair (2009). Duden. Fit für das Bachelor-Studium. Grundwissen Grammatik. Mannheim, Leipzig, Wien, Zürich: Dudenverlag.

Handwerker, Brigitte (2009). Sprachunterricht als Instruktion und Inputverarbeitung. Zeitschrift für Literaturwissenschaft und Linguistik 39(1), 96-111.

Heidolph, Karl Erich, Walter Flämig und Wolfgang Motsch (1981). Grundzüge einer deutschen Grammatik. Berlin: Akademie Verlag.

Helbig, Gerhard (1992a). Probleme der Valenz- und Kasustheorie. Konzepte der Sprach- und Literaturwissenschaft. Tübingen: Niemeyer.

Helbig, Gerhard (1992b). Wieviel Grammatik braucht der Mensch? Deutsch als Fremdsprache 29(3), 160-165.

Hennig, Mathilde (2012). Was ist ein Grammatikfehler? In Susanne Günther, Wolfgang Imo, Dorothee Meer, und Jan Georg Schneider (Hg.), Kommunikation und Öffentlichkeit. Sprachwissenschaftliche Potenziale zwischen Empirie und Norm, Reihe germanistische Linguistik, S. 121-148. Berlin, Boston: De Gruyter.

Herder, Johann Gottfried von (1810). Von den Vortheilen und Nachtheilen der heutigen StudienMethode. In Johann Georg Müller (Hg.), Johann Gottfried von Herders sämmtliche Werke. Zur Philosophie und Geschichte. Sohpron. Gesammelte Schulreden., Bd. 12, S. 10-18. Tübingen: Cotta'sche Buchhandlung. URL https://reader.digitale-sammlungen.de/de/fs1/ object/display/bsb10713478_00005.html.

Herder, Johann Gottfried von (1972). Journal meiner Reise im Jahr 1769. Leipzig: Reclam jun. Heringer, Hans Jürgen (1974). Linguistik und Didaktik. Linguistik und Didaktik 4(18), 1 19-130.

Heringer, Hans Jürgen (1978). Gar grausam rächet die Grammatik sich gegen ihre Verächter. In Ulrich Engel und Sigfried Grosse (Hg.), Grammatik und Deutschunterricht, Jahrbuch 1977 des Instituts für deutsche Sprache. Düsseldorf: Schwann.

Heringer, Hans Jürgen (2014). Deutsche Grammatik und Wortbildung in 125 Fragen und Antworten. UTB. Tübingen: Francke.

Hirschmann, Hagen, Anke Lüdeling, Ines Rehbein, Marc Reznicek und Amir Zeldes (2013). Underuse of Syntactic Categories in Falko. A Case Study on Modification. In Sylviane Granger, Gaetanelle Gilquin, und Fanny Meunier (Hg.), Twenty years of learner corpus research: Looking back, Moving ahead. Corpora and Language in Use - Proceedings 1, S. 223-234. Louvain la Neuve: Presses universitaires de Louvain.

Hoffmann, Ludger (2011). Zwischen wissenschaftlicher Grammatik und Schulgrammatik: die Terminologie. Osnabrücker Beiträge zur Sprachtheorie 79, 33-56.

Housen, Alex, Michel Pierrard und Siska Van Daele (2005). Rule Complexity and the Efficacy of Explicit Grammar Instruction. In Alex Housen und Michel Pierrard (Hg.), Investigations in Instructed Second Language Acquisition, S. 235-269. Berlin: De Gruyter.

Humboldt, Wilhelm von (1836). Über die Verschiedenheit des menschlichen Sprachbaues und ihren Einfluß auf die geistige Entwickelung des Menschengeschlechts. Berlin: Druckerei der Königlichen Akademie der Wissenschaften.

Häcker, Roland (2009). Wie viel? Wozu? Warum? Grammatik in der Schule. In Marek Konopka und Bruno Strecker (Hg.), Deutsche Grammatik - Regeln, Normen. Sprachgebrauch. 
Jahrbuch des Instituts für deutsche Sprache 2008, S. 309-332. Berlin, New York: De Gruyter.

Höllein, Dagobert (2019). Präpositionalobjekt vs. Adverbial. Die semantischen Rollen der Präpositionalobjekte. Linguistik - Impulse und Tendenzen. Berlin, Boston: De Gruyter.

Ickelsamer, Valentin (1535). Teutsche Grammatica. Augsburg. URL https://epub.ub.unimuenchen.de/12188/.

Ingendahl, Werner (1999). Sprachreflexion statt Grammatik. Ein didaktisches Konzept für alle Schulstufen. Reihe Germanistische Linguistik. Tübingen: Niemeyer.

Ivo, Hubert (2011). Wissenschaftliche Schulgrammatik des Deutschen? Osnabrücker Beiträge zur Sprachtheorie 79, 13-32.

Ivo, Hubert und Eva Neuland (1991). Grammatisches Wissen. Skizze einer empirischen Untersuchung über Art, Umfang und Verteilung grammatischen Wissens (in der Bundesrepublik). Diskussion Deutsch 121(1991), 437-493.

Jacobs, Joachim (1994). Kontra Valenz. Trier: WVT Wissenschaftlicher Verlag Trier.

Jolly, Julius (1874). Schulgrammatik und Sprachwissenschaft. Studien über die Neugestaltung des grammatischen Unterrichts nach den Ergebnissen un der Methode der vergleichenden Sprachwissenschaft. München: Ackermann. URL http://reader.digitale-sammlungen.de/ de/fs1/object/display/bsb11186019_00005.html.

Kany, Werner und Hermann Schöler (2007). Fokus: Sprachdiagnostik. Leitfaden zur Sprachstandsbestimmung im Kindergarten. Berlin: Cornelsen Scriptor.

Karmiloff-Smith, Annette (1992). Beyond Modularity. A Developmental Perspective on Cognitive Science. Cambridge: The MIT Press.

Keller, Rudi (1980). Zum Begriff des Fehlers im muttersprachlichen Unterricht. In Dieter Cherubim (Hg.), Fehlerlinguistik. Beiträge zum Problem der sprachlichen Abweichung, Reihe germanistische Linguistik, S. 23-42. Tübingen: Niemeyer.

Kultusministerkonferenz (1982). Verzeichnis grundlegender grammatischer Fachausdrücke (von der Kultusministerkonferenz zustimmend zur Kenntnis genommen am 26.2.1982. URL https://www.kmk.org/fileadmin/Dateien/veroeffentlichungen_beschluesse/1982/ 1982_02_26-Verzeichnis-grammatischer-Fachausdruecke.pdf, letzter Zugriff: 22.11.17.

Kultusministerkonferenz (2019). Verzeichnis grundlegender grammatischer Fachausdrücke (von der Kultusministerkonferenz zustimmend zur Kenntnis genommen am 7. November 2019. URL https://grammis.ids-mannheim.de/vggf, letzter Zugriff: 25.04.20.

Kupietz, Marc und Holger Keibel (2009). Gebrauchsbasierte Grammatik: Statistische Regelhaftigkeit. In Marek Konopka und Bruno Strecker (Hg.), Deutsche Grammatik - Regeln, Normen, Sprachgebrauch. Jahrbuch des Instituts für deutsche Sprache 2008, S. 33-50. Berlin, New York: De Gruyter.

Köller, Wilhelm (1997). Funktionaler Grammatikunterricht. Tempus, Genus, Modus: Wozu wurde das erfunden? (4. Aufl.). Baltmannsweiler: Schneider Hohengehren.

Langacker, Ronald W. (1991). Foundations of Cognitive Grammar, Bd. 2. Descriptive Application. Stanford: Stanford University Press.

Lüdeling, Anke (2008). Mehrdeutigkeiten und Kategorisierung: Probleme bei der Annotation von Lernerkorpora. In Maik Walter und Patrick Gommes (Hg.), Fortgeschrittene Lernervarietäten, S. 119-140. Tübingen: Niemeyer.

Lütke, Beate (2011). Deutsch als Zweitsprache in der Grundschule. Eine Untersuchung zum Erlernen lokaler Präpositionen. DaZ-Forschung. Berlin, Boston: De Gruyter.

Matthews, Peter Hugoe (1981). Syntax. Cambridge textbooks in linguistics. Cambridge: Cambridge University Press. 
Menzel, Wolfgang (1999). Grammatik-Werkstatt. Theorie und Praxis eines prozessorientierten Grammatikunterrichts für die Primar- und Sekundarstufe. Seelze-Velber: Kallmeyersche Verlagsbuchhandlung.

Müller, Stefan (2010). Grammatiktheorie (2, überarb. Aufl.). Stauffenburg Einführungen. Tübingen: Stauffenburg.

Nietzsche, Friedrich (2017). Über die Zukunft unserer Bildungs-Anstalten. Berlin: Contumax $\mathrm{GmbH}$.

Nilsson, Torsten Per (2002). Das Dilemma der deutschen Schulgrammatik. Thesis. URL http:// duepublico.uni-duisburg-essen.de/servlets/DocumentServlet?id=5469.

Ossner, Jacob (1993). Wege zur Grammatik. Ein weiterer Versuch zu der Frage: „Wieviel Grammatik braucht der Mensch?“. In Földes Csaba (Hg.), Germanistik und Deutschlehrerausbildung. Festschrift zum hundertsten Jahrestag der Gründung des Lehrstuhls für deutsche Sprache und Literatur an der pädagogischen Hochschule Szeged, S. 323-339. Wien: Praesens.

Ossner, Jacob (2008). Sprachdidaktik Deutsch. Eine Einführung für Studierende. Paderborn, München, Wien, Zürich: Schöningh.

Ossner, Jacob (2015). Grammatik im Studium. In Arne Ziegler und Klaus-Michael Köpcke (Hg.), Deutsche Grammatik in Kontakt. Deutsch als Zweitsprache in Schule und Unterricht, Linguistik - Impulse und Tendenzen, S. 63-84. Berlin, Boston: De Gryuter.

Pasch, Renate (1977). Zum Status der Valenz. In Beiträge zur semantischen Analyse., Linguistische Studien, Reihe A Arbeitsberichte. Berlin: Akademie der Wissenschaften der DDR/Zentralinstut für Sprachwissenschaft. URL https://ids-pub.bsz-bw.de/frontdoor/ index/index/docld/7343.

Pienemann, Manfred (1989). Is language teachable? Psycholinguistic experiments and hypothesis. Applied Linguistics 10(1), 52-79.

Polenz, Peter von (2002). Sprachgeschichte und Gesellschaftsgeschichte von Adelung bis heute. In Dieter Cherubim, Karlheinz Jakob, und Angelika Linke (Hg.), Neue deutsche Sprachgeschichte. Mentalitäts-, kultur- und sozialgeschichtliche Zusammenhänge, S. 1-24. Berlin, New York: De Gruyter.

Primus, Beatrice (2015). Semantische Rollen und Satzgliedanalyse im Grammatikunterricht. In Birgit Mesch und Björn Rothstein (Hg.), Was tun mit dem Verb? Über die Möglichkeit und Notwendigkeit einer didaktischen Neuerschließung des Verbs, Germanistische Linguistik. Berlin, Boston: De Gruyter.

Reis, Marga (1982). Zum Subjektbegriff im Deutschen. In Werner Abraham (Hg.), Satzglieder im Deutschen, Studien zur deutschen Grammatik, S. 171-211. Tübingen: Narr.

Richtiges und gutes Deutsch. Das Wörterbuch der sprachlichen Zweifelsfälle (2011). Der Duden in zwölf Bänden. Band 9 (7. vollständig überarbeitetete und aktualisierte Aufl.). Herausgegeben von der Dudenredaktion unter Mitarbeit von Peter Eisenberg und Jan Georg Schneider.

Ries, John (1894). Was ist Syntax? Ein kritischer Versuch. Marburg: Elwertsche Verlagsbuchhandlung. URL https://archive.org/stream/wasistsyntaxein00riesgoog\#page/n3/ mode/2up.

Risel, Heinz (1999). Schlaglichter auf Wissensbestände. Anmerkungen zu „Grammatikbiographien“. In Peter Klotz und Ann Peyer (Hg.), Wege und Irrwege sprachlich-grammatischer Sozialisation, S. 53-60. Baltmannsweiler: Schneider Hohengehren.

Ronneberger-Sibold, Elke (2010). Die deutsche Nominalklammer: Geschichte, Funktion, typologische Bewertung. In Arne Ziegler (Hg.), Historische Textgrammatik und historische 
Syntax des Deutschen. Traditionen, Innovationen, Perspektiven, Bd. 1. Diachronie, Althochdeutsch, Mittelhochdeutsch. Berlin: De Gruyter.

Ryle, Gilbert (2009). The Concept of Mind (60. Aufl.). London, New York: Routledge.

Röber, Christa (2011). Konzepte des Erwerbs der Groß-/Kleinschreibung. In Ursula Bredel und Tilo Reißig (Hg.), Weiterführender Orthographieerwerb, Deutschunterricht in Theorie und Praxis, S. 296-317. Hohengehren: Schneider Verlag.

Schlipphack, Isabelle (2012). Generative Grammatik für die Schule. Marburg: Tectum.

Schmitz, Ulrich (2003). Satzzeigen. Wie oft kann das grammatische Abendland noch untergehen? Mitteilungen des deutschen Germanistenverbandes 2-3, 34-44.

Schottel, Justus Georg (1663). Ausführliche Arbeit Von der Teutschen HauptSprache. Braunschweig: C. F. Zilligern. URL http://diglib.hab.de/drucke/ko-306/start.htm.

Schäfer, Roland (2016). Einführung in die grammatische Beschreibung des Deutschen (2., überarb. Aufl.). Textbooks in Language Sciences 2. Berlin: Language Science Press.

Schäfer, Roland und Ulrike Sayatz (2017). Wie viel Grammatik braucht das Germanistikstudium? Zeitschrift für Germanistische Linguistik 42(2), 221-255.

Sitta, Horst und Hans Josef Tymister (1978). Linguistik und Unterricht. Reihe Germanistische Linguistik. Tübingen: Niemeyer.

Stein, Stephan (1995). Formelhafte Sprache. Untersuchungen zu ihren pragmatischen und kognitiven Funktionen im gegenwärtigen Deutsch. Beiträge zur Sprachwissenschaft. Frankfurt am Main u. a.: Lang.

Steinig, Wolfgang und Hans-Werner Huneke (2015). Sprachdidaktik Deutsch. Eine Einführung (5., neu bearbeitete und erw. Aufl.). Grundlagen der Germanistik. Berlin: Erich Schmidt Verlag.

Sütterlin, Ludwig (1907). Deutsche Sprache der Gegenwart. Ein Handbuch für Lehrer und Studierende. (2., stark veränd. Aufl.). Leipzig: Voigtländers Verlag.

Takada, Hiroyuki (1998). Grammatik und Sprachwirklichkeit von 1640-1700: zur Rolle deutscher Grammatiker im schriftsprachlichen Ausgleichsprozeß. Germanistische Linguistik. Tübingen: Niemeyer.

Tesnière, Lucien (1959). Éléments de syntaxe structurale. Paris: Klincksieck.

Tomasello, Michael (1999). The Cultural Origins of Human Cognition. Harvard: Harvard University Press.

Topalovic, Elvira und Susanne Dünschede (2014). Weil Grammatik im Lehrplan steht. Bundesweite Umfrage zur Grammatik in der Schule. Der Deutschunterricht 3(2014), 76-81.

Ulshöfer, Robert (1967). Methodik des Deutschunterrichts. Unterstufe (3., durchges. Aufl.), Bd. 1. Stuttgart: Klett.

Weinrich, Harald (2003). Textgrammatik der deutschen Sprache (Unter Mitarbeit von Maria Thurmair, Eva Brendl, Eva-Maria Brendl. 2., rev. Aufl.). Hildesheim, Zürich, New-York: Olms.

Weisgerber, Leo (1957). Das Tor zur Muttersprache (3. Aufl.). Düsseldorf: Schwann.

Welke, Klaus (1988). Einführung in die Valenz- und Kasustheorie. Leipzig: VEB Bibliographisches Institut.

Welke, Klaus (2005). Deutsche Syntax funktional. Perspektiviertheit syntaktischer Strukturen. (2., bearb. Aufl.). Stauffenburg Linguistik. Tübingen: Stauffenburg.

Welke, Klaus (2007). Einführung in die Satzanalyse. Die Bestimmung der Satzglieder im Deutschen. De Gruyter Studienbuch. Berlin, New York: De Gruyter.

Welke, Klaus (2011). Valenzgrammatik des Deutschen. Eine Einführung. De Gruyter Studium. Berlin, New York: De Gruyter. 
Welke, Klaus (2016). Attribution unter konstruktionsgrammatischem Aspekt. In Mathilde Hennig (Hg.), Komplexe Attribution. Ein Nominalstilphänomen aus sprachhistorischer, grammatischer, typologischer und funktionalistischer Perspektive, Linguistik - Impulse und Tendenzen, S. 57-95. Berlin, Boston: De Gruyter Mouton.

Welke, Klaus (2019). Konstruktionsgrammatik des Deutschen. Ein sprachgebrauchsbezogener Ansatz. Linguistik - Impulse und Tendenzen. Berlin, Boston: De Gruyter.

Wittgenstein, Ludwig (1990). Philosophische Untersuchungen. In Peter Philipp (Hg.), Wittgenstein. Tractatus logicus-philosophicus (1922). Philosophische Untersuchungen (1953), S. 95-423. Leipzig: Reclam.

Wurst, Raimund Jakob (1867). Praktische Sprachdenklehre für Volksschulen und die Elementarklassen der Gymnasial- und Real-Anstalten. Nach Dr. K. F. Becker's Ansichten über die Behandlung des Unterrichts in der Muttersprache. (68. Aufl.). Stuttgart: Verlagsbuchhandlung Carl Mäcken. URL https://reader.digitale-sammlungen.de/de/fs1/object/ display/bsb10584623_00005.html.

Wurzel, Wolfgang Ulrich (1994). Grammatisch initiierter Wandel. Unter Mitarb. von Andreas Bittner und Dagmer Bittner. Bochum-Essener Beiträge zur Sprachwandelforschung. Sprachdynamik. Auf dem Weg zu einer Typologie sprachlichen Wandels. Band 1. Bochum: Universitätsverlag Brockmeyer.

Zifonun, Gisela, Ludger Hoffmann und Bruno Strecker (1997). Grammatik der deutschen Sprache, Bd. 1 in Schriften des Instituts für deutsche Sprache. Berlin, New York: De Gruyter. 